\title{
On the Origin of Ultraslow Spontaneous $\mathrm{Na}^{+}$Fluctuations in
}

\section{Neurons of the Neonatal Forebrain}

10 Short Title: Ultraslow Spontaneous $\mathrm{Na}^{+}$Fluctuations in the Neonatal Forebrain

11

$14 \$$ These two authors contributed equally to this manuscript

$16{ }^{*}$ Corresponding Author

174202 E Fowler Ave, ISA 2019

18 Tampa, FL 33620, USA

19 Email: gullah@usf.edu

20 Tel: 813-974-0698 


\section{Abstract}

Spontaneous neuronal and astrocytic activity in the neonate forebrain is believed to drive

23 the maturation of individual cells and their integration into complex brain-region-specific

24 networks. The previously reported forms include bursts of electrical activity and oscillations in

25 intracellular $\mathrm{Ca}^{2+}$ concentration. Here, we use ratiometric $\mathrm{Na}^{+}$imaging to demonstrate spontaneous

26 fluctuations in the intracellular $\mathrm{Na}^{+}$concentration of CA1 pyramidal neurons and astrocytes in

27 tissue slices obtained from the hippocampus of mice at postnatal days 2-4 (P2-4). These occur at

28 very low frequency $(\sim 2 / \mathrm{h})$, can last minutes with amplitudes up to several $\mathrm{mM}$, and mostly

29 disappear after the first postnatal week. To further study the mechanisms that may generate such

30 spontaneous fluctuations in neurons, we model a network consisting of pyramidal neurons and

31 interneurons. Experimentally observed $\mathrm{Na}^{+}$fluctuations are mimicked when GABAergic

32 inhibition in the simulated network is inverted. Both our experiments and computational model

33 show that the application of tetrodotoxin to block voltage-gated $\mathrm{Na}^{+}$channels or of inhibitors

34 targeting GABAergic signaling respectively, significantly diminish the neuronal $\mathrm{Na}^{+}$fluctuations.

35 On the other hand, blocking a variety of other ion channels, receptors, or transporters including

36 glutamatergic pathways, does not have significant effects. In addition, our model shows that the

37 amplitude and duration of $\mathrm{Na}^{+}$fluctuations decrease as we increase the strength of glial $\mathrm{K}^{+}$uptake.

38 Furthermore, neurons with smaller somatic volumes exhibit fluctuations with higher frequency

39 and amplitude. As opposed to this, the larger relative size of the extracellular with respect to

40 intracellular space observed in neonatal brain exerts a dampening effect. Finally, our model also

41 predicts that these periods of spontaneous $\mathrm{Na}^{+}$influx leave neonatal neuronal networks more

42 vulnerable to hyperactivity when compared to mature brain. Taken together, our model thus 
bioRxiv preprint doi: https://doi.org/10.1101/2020.05.29.123026; this version posted May 29, 2020. The copyright holder for this preprint (which

was not certified by peer review) is the author/funder, who has granted bioRxiv a license to display the preprint in perpetuity. It is made available under aCC-BY 4.0 International license.

43 confirms the experimental observations, and offers additional insight into how the neonatal

44 environment shapes early signaling in the brain.

45 


\section{Author Summary}

Spontaneous neuronal and astrocytic activity during the early postnatal period is crucial to

48 the development and physiology of the neonate forebrain. Elucidating the origin of this activity is

49 key to our understanding of the cell maturation and formation of brain-region-specific networks.

50 This study reports spontaneous, ultraslow, large-amplitude, long-lasting fluctuations in the

51 intracellular $\mathrm{Na}^{+}$concentration of neurons and astrocytes in the hippocampus of mice at postnatal

52 days 2-4 that mostly disappear after the first postnatal week. We combine ratiometric $\mathrm{Na}^{+}$imaging

53 and pharmacological manipulations with a detailed computational model of neuronal networks in

54 the neonatal and adult brain to provide key insights into the origin of these $\mathrm{Na}^{+}$fluctuations.

55 Furthermore, our model predicts that these periods of spontaneous $\mathrm{Na}^{+}$influx leave neonatal

56 neuronal networks more vulnerable to hyperactivity when compared to mature brain. 


\section{Introduction}

Spontaneous neuronal activity is a hallmark of the developing central nervous system [1],

59 and has been described in terms of intracellular $\mathrm{Ca}^{2+}$ oscillations both in neurons and astrocytes

60 [2-5] and bursts of neuronal action potentials [6-8]. This activity is believed to promote the

61 maturation of individual cells and their integration into complex brain-region-specific networks

$62[1,9-11]$. In the rodent hippocampus, early network activity and $\mathrm{Ca}^{2+}$ oscillations are mainly

63 attributed to the excitatory role of GABAergic transmission originating from inhibitory neurons

$64[7,12-14]$.

The excitatory action of GABAergic neurotransmission is one of the most notable

66 characteristics that distinguish neonate brain from the mature brain, where GABA typically

67 inhibits neuronal networks $[1,7,8,10-12,15-17]$. While recent work has also called the inhibitory

68 action of GABA on cortical networks into question [18], there are many other pathways that could

69 play a significant role in the observed spontaneous activity in neonate brain (discussed below).

70 Additional key features of the early network oscillations in the hippocampus include their

71 synchronous behavior across most of the neuronal network, modulation by glutamate, recurrence

72 with regular frequency, and a limitation to early post-natal development $[2,7,12]$.

More recently, Felix and co-workers [5] reported a new form of seemingly spontaneous

74 activity in acutely isolated tissue slices of hippocampus and cortex of neonatal mice. It consists of

75 spontaneous fluctuations in intracellular $\mathrm{Na}^{+}$both in astrocytes and neurons, which occur in $\sim 25 \%$

76 of pyramidal neurons and $\sim 40 \%$ of astrocytes tested. $\mathrm{Na}^{+}$fluctuations are ultraslow in nature,

77 averaging $\sim 2$ fluctuations/hour, are not synchronized between cells, and are not significantly

78 affected by an array of pharmacological blockers for various channels, receptors, and transporters.

79 Only using the voltage-gated $\mathrm{Na}^{+}$channel (VGSC) blocker tetrodotoxin (TTX) diminished the $\mathrm{Na}^{+}$ 
80 fluctuations in neurons and astrocytes, indicating that they are driven by the generation of neuronal

81 action potentials. In addition, neuronal fluctuations were significantly reduced by the application

82 of the $\mathrm{GABA}_{\mathrm{A}}$ receptor antagonist bicuculline, suggesting the involvement of GABAergic

83 neurotransmission.

84 This paper follows up on the latter study [5], and uses dual experiment-theory approach to 85 systematically confirm, and further investigate the properties of neuronal $\mathrm{Na}^{+}$fluctuations in the neonate hippocampal CA1 area and to identify the pathways that generate and shape them.

87 Notably, a range of factors that play a key role in controlling the dynamics of extra- and 88 intracellular ion concentrations, are not fully developed in the neonate forebrain [13, 19-22]. These

89 factors, such as the cellular uptake capacity of $\mathrm{K}^{+}$from the extracellular space (ECS), the 90 expression levels of the three isoforms $(\alpha 1, \alpha 2$, and $\alpha 3)$ of the $\mathrm{Na}^{+} / \mathrm{K}^{+}$pump that restore resting

$91 \mathrm{Na}^{+}$and $\mathrm{K}^{+}$concentrations, the ratio of intra- to extracellular volumes, and the magnitude of

92 relative shrinkage of the ECS in response to neuronal stimulus, all increase with age and cannot

93 be easily manipulated experimentally [19]. The gap-junctional network between astrocytes is also

94 less developed in neonates and therefore has a lower capacity for the spatial buffering of ions,

95 neurotransmitters released by neurons, and metabolites [19,21]. At the same time, the synaptic

96 density and expression levels of most isoforms of AMPA and NMDA receptors are very low in

97 neonates and only begin to increase rapidly during the second week [13]. Additionally, while

98 GABAergic synapses develop earlier than their glutamatergic counterparts, synaptogenesis is

99 incomplete and ongoing. Therefore, synapses of varying strengths exist across the network. Each

100 of these aspects impacts the others and their individual specific roles in the early spontaneous

101 activity is consequently difficult to test experimentally. Their involvement in neonatal $\mathrm{Na}^{+}$ 
102 fluctuations will therefore be addressed for the first time by the data-driven modelling approach

103 here.

104 We employ ratiometric $\mathrm{Na}^{+}$imaging in tissue slices of the hippocampal CA1 region

105 obtained from neonate animals at postnatal days 2-4 (P2-4) and juveniles at P14-21 to record

106 intracellular $\mathrm{Na}^{+}$fluctuations in both age groups. We begin by reporting the key statistics about

107 spontaneous $\mathrm{Na}^{+}$fluctuations observed in neonates and juveniles. Next, we develop a detailed

108 network model, consisting of pyramidal cells and inhibitory neurons, which also incorporates the

109 exchange of $\mathrm{K}^{+}$in the ECS with astrocytes and perfusion solution in vitro (or vasculature in intact

110 brain). Individual neurons are modeled by Hodgkin-Huxley type formalism for membrane

111 potential and rate equations for intra- and extracellular ion concentrations. In addition to closely

112 reproducing our experimental results, the model provides new key insights into the origin of 113 spontaneous slow $\mathrm{Na}^{+}$oscillations in neonates. Furthermore, our model also predicts that the 114 network representing a developing brain is more hyperexcitable when compared to mature brain.

\section{Results}

117 Pyramidal neurons in neonate hippocampus exhibit spontaneous ultraslow $\mathrm{Na}^{+}$fluctuations.

118 Acutely isolated parasagittal slices from hippocampi of neonatal mice (P2-4) were bolus-

119 stained with the sodium-sensitive ratiometric dye SBFI-AM along the CA1 region (Figure 1A1).

120 Experimental measurements lasted for 60 minutes, with an imaging frequency of $0.2 \mathrm{~Hz}$.

121 Astrocytes were identified via SR101 staining (Figure 1A1), and were analyzed separately to the

122 neurons in the pyramidal layer. Out of the measured cells, $26 \%$ of neurons $(n=63 / 243)$ and $38 \%$

123 of astrocytes $(n=36 / 97)$ showed detectable fluctuations in their intracellular $\mathrm{Na}^{+}$concentrations

124 (Figure 1A2, 1B). Detection threshold was calculated individually for each cell, and was defined 
125 as being 3 times the standard deviation of the baseline noise of each ROI analyzed (this ranged

126 from 0.28 to $2.04 \mathrm{mM}$ ). Astrocyte $\mathrm{Na}^{+}$fluctuations were $10.3 \pm 0.7$ minutes long, at a frequency

127 of $1.3 \pm 0.2$ signals/hour and with average amplitudes of $2.4 \pm 0.2 \mathrm{mM}$. Neuronal $\mathrm{Na}^{+}$fluctuations

128 had an average duration of $8.6 \pm 0.4$ minutes. They occurred at a frequency of $2 \pm 0.2$

129 fluctuations/hour with average amplitudes of $2.7 \pm 0.12 \mathrm{mM}$. The high variability in the shapes of

130 fluctuations is demonstrated in Figure 1A2. Apparent synchronicity between cells of the same or

131 different classes was only observed rarely, confirming the observations reported in our earlier study

$132[5]$.

133 To investigate the developmental profile of the fluctuations, the same protocol was repeated

134 in hippocampal tissue from juvenile (P14-20) mice. Here, only 5.3\% of all measured neurons

$135(n=7 / 132)$ and $4.3 \%$ of all measured astrocytes $(n=1 / 23)$ showed fluctuations in their intracellular

$136 \mathrm{Na}^{+}$concentrations (Figure 1B). This strong reduction confirmed the significant down-regulation

137 of spontaneous $\mathrm{Na}^{+}$oscillations from neonatal to juvenile animals reported recently [5]. However,

138 the properties of the neuronal fluctuations themselves remained unchanged during postnatal

139 development, with the average amplitude, frequency, and duration being $1.9 \pm 0.13 \mathrm{mM}, 2 \pm 0.3$

140 fluctuations/hour, and $6.5 \pm 0.9$ minutes in juvenile tissue (Figure 1C).

142 Spontaneous $\mathrm{Na}^{+}$fluctuations are reproduced by a computational model with excitatory

143 GABAergic neurotransmission.

144 To explore the properties and mechanisms of neonate neuronal $\mathrm{Na}^{+}$fluctuations, we

145 developed a computational model consisting of CA1 pyramidal cells and inhibitory neurons as

146 detailed in the Methods section. Resulting typical time traces of intracellular $\mathrm{Na}^{+}$from four

147 randomly selected excitatory neurons in a network representative of the juvenile hippocampus 
148 (where GABAergic neurotransmission is inhibitory) are shown in the right panel of Figure 2A.

$149 \mathrm{Na}^{+}$in individual neurons shows minor irregular fluctuations of less than $0.05 \mathrm{mM}$ around the

150 resting values mostly because of the random synaptic inputs from the network. However, no clear

151 large-amplitude fluctuations can be seen in the network. To mimic neonates, we invert the sign of

152 I-to-E and I-to-I synaptic inputs, making the GABAergic neurotransmission excitatory. The

153 inverted inhibition results in the occurrence of spontaneous $\mathrm{Na}^{+}$fluctuations in the low $\mathrm{mM}$ range

154 in individual neurons that persist for several minutes (Figure 2A, left column). In some cases, the

155 peak amplitude of oscillations reached values of more than $5 \mathrm{mM}$.

156 The simulated data shows a comparable pattern of irregular fluctuations to the experimental

157 results (Figure 2B). The properties of these events are very similar-with peak amplitudes mostly

158 in the 2-3 $\mathrm{mM}$ range and durations spanning over several minutes. However, the simulated data

159 also appears to show a high rate of low amplitude spiking, apparently absent from the experimental

160 traces. As mentioned above, the detection threshold for experimental data ranged from 0.28 to 2.04

$161 \mathrm{mM}$ (see also Figure 2B), and the imaging frequency was kept at $0.2 \mathrm{~Hz}$ in order to prevent

162 phototoxic effects during the long-lasting continuous recordings. Fast, low amplitude transients as

163 revealed in simulated experiments are thus below the experimental detection threshold- as

164 indicated in Figure 2.

165

166

Neonate network does not exhibit spontaneous fluctuations in $\left[K^{+}\right]_{0}$.

167 Since the dynamics of $\mathrm{Na}^{+}$and $\mathrm{K}^{+}$are generally coupled in mature brain, we next look at

$168 \mathrm{~K}^{+}$concentration in the ECS of individual neurons $\left(\left[\mathrm{K}^{+}\right]_{\mathrm{o}}\right)$ in the network to see if it exhibits similar

169 spontaneous fluctuations. A sample trace for a randomly selected neuron is shown in Figure 3A

170 (gray). As clear from the figure, there are only minimal fluctuations in $\left[\mathrm{K}^{+}\right]_{\mathrm{o}}$ (peak amplitudes of 
171 residual changes are $<0.05 \mathrm{mM}$ ) with respect to the resting state when compared to the much

172 larger $\left[\mathrm{Na}^{+}\right]_{\mathrm{i}}$ fluctuations in the same cell (gray line in Figure 3B). Next, we recorded $\left[\mathrm{K}^{+}\right]_{\mathrm{o}}$ traces

173 for all pyramidal neurons in the network and calculated the mean $\left[\mathrm{K}^{+}\right]_{\mathrm{o}}$ (averaged over all

174 excitatory neurons). The mean $\left[\mathrm{K}^{+}\right]_{\mathrm{o}}$ as a function of time shows that all excitatory neurons in the

175 network exhibit very small changes in the $\left[\mathrm{K}^{+}\right]_{\mathrm{o}}$, which are essentially canceled out at the network

176 level (Figure 3A, black line). The mean intracellular $\mathrm{Na}^{+}$fluctuates slightly more than the mean

$177\left[\mathrm{~K}^{+}\right]_{\mathrm{o}}$ (Figure 3B, black line). However, a comparison between the traces showing the average $\mathrm{Na}^{+}$

178 over all excitatory neurons in the network and that from the single neuron indicates that the

179 amplitude of $\mathrm{Na}^{+}$fluctuations varies from cell to cell and that they are not necessarily phase-

180 locked. All these observations are in agreement with experimental results reported above.

182 The model replicates the observed effects of TTX and other blockers

183 We next performed imaging experiments in which various blockers were applied. Addition

184 of $0.5 \mu \mathrm{M}$ TTX reduced the number of neurons showing fluctuations to $4 \%(n=7 / 167)$, suggesting

185 a dependence on action potential generation via the opening of voltage-gated $\mathrm{Na}^{+}$channels (Figure

186 4A). However, blocking of glutamatergic receptors with a cocktail containing APV (100 $\mu \mathrm{M})$,

187 NBQX $(25 \mu \mathrm{M})$, and MPEP $(25 \mu \mathrm{M})$ (targeting NMDA, AMPA/kainate, and mGluR5 receptors,

188 respectively) had no effect on the number of neurons showing fluctuations $(21 \%$ active, $n=33 / 155)$

189 (Figure 4A). Additionally, the role of GABAergic signaling was tested via combined application

190 of bicuculline $(10 \mu \mathrm{M}), \mathrm{CGP}-55845(5 \mu \mathrm{M})$, NNC-711 $(100 \mu \mathrm{M})$, and SNAP-5114 $(100 \mu \mathrm{M})$

191 (antagonists for $\mathrm{GABA}_{\mathrm{A}}$ receptors, GABA $\mathrm{B}$ receptors, GABA transporters GAT1, and GAT2/3,

192 respectively). This combination of antagonists reduced the number of active neurons to a similar

193 degree as TTX (3\% active, $n=5 / 158)$ (Figure 4A). These data are concordant with the results 
194 previously published [5], and suggest that the slow fluctuations in intracellular $\mathrm{Na}^{+}$are produced

195 by the accumulation of $\mathrm{Na}^{+}$during trains of action potentials, triggered by GABAergic

196 transmission.

197 The pharmacological profile of the experimentally observed $\mathrm{Na}^{+}$fluctuations in the 198 neonatal brain summarized above strongly suggests that the excitatory effect of GABAergic 199 neurotransmission plays a key role in their generation, whereas glutamatergic activity contributes 200 very little. Before making model-based predictions, we first confirm that our model reproduces 201 these key observations in our experiments. We first incorporate the effect of TTX in the model by 202 setting the peak conductance of voltage-gated $\mathrm{Na}^{+}$channels to zero. We also mimic the effect of 203 blocking ionotropic glutamate receptors with CNQX and APV by setting E-to-E and E-to-I 204 synaptic conductances to zero. Finally, we mimic the effect of blocking GABAergic transmission 205 on the activity of the network, and set the I-to-I and I-to-E synaptic currents to zero, thereby 206 removing all $\mathrm{GABA}_{\mathrm{A}}$-receptor-related effects. The model results are largely in line with 207 observations, where we see that inhibiting GABA-related currents and voltage-gated $\mathrm{Na}^{+}$channels 208 mostly eliminate $\mathrm{Na}^{+}$fluctuations and blocking NMDA and AMPA synaptic inputs has little effect 209 on the observed spontaneous activity (Figure 4B).

211 Spontaneous $\mathrm{Na}^{+}$fluctuations are shaped by neuronal morphology and glial $\mathrm{K}^{+}$uptake capacity.

212 As pointed out above, significant changes occur in the physical and functional properties

213 of the neurons during postnatal maturation at the synaptic, single cell, and network levels [13, 19].

214 Therefore, we use the model to examine if changes in some key physical and functional

215 characteristics of the network such as the neuronal radius $\left(\mathrm{r}_{\mathrm{in}}\right)$, the ratio of ICS to ECS $(\beta)$, and 216 glial $\mathrm{K}^{+}$uptake rate play any role in the observed $\mathrm{Na}^{+}$fluctuations. In the following, we show $\mathrm{Na}^{+}$ 
217 time traces for four randomly selected excitatory neurons. We observe that smaller neurons in

218 general exhibit larger $\mathrm{Na}^{+}$fluctuations ( $\mathrm{p}>0.001$, Figure $5 \mathrm{~A}$, left panels). Both the amplitude and

219 frequency of fluctuations decrease as we increase $r_{\text {in }}$ (Figure $5 \mathrm{~A}$, center panels). The panel on the

220 right in Figure 5A (and Figure 5B, C) shows the average amplitude of $\mathrm{Na}^{+}$fluctuations as we

221 change the parameter of interest.

The observed fraction of ECS with respect to ICS in neonates is approximately $40 \%$ ( $\beta=$

neonates does not favor the generation of large $\mathrm{Na}^{+}$fluctuations, but on the contrary dampens ion changes.

The expression levels of astrocytic channels and transporters involved in $\mathrm{K}^{+}$uptake

$231\left(\mathrm{Na}^{+} / \mathrm{K}^{+}\right.$ATPase, Kir4.1 channels, and $\mathrm{Na}^{+} / \mathrm{K}^{+} / \mathrm{Cl}^{-}$co-transporter 1 (NKCC1)) and connexins

232 forming gap junctions are low in neonates [20, 21]. Astrocytes in the neonate brain, therefore, have

233 a lower capacity for uptake of extracellular $\mathrm{K}^{+}$released by neurons [19]. To analyze the influence

234 of glial $\mathrm{K}^{+}$uptake, we varied the maximum glial $\mathrm{K}^{+}$uptake strength in the model from $12 \mathrm{mM} / \mathrm{sec}$

235 (significantly lower than $66 \mathrm{mM} / \mathrm{sec}$ - the value used for mature neurons in [27]) to $96 \mathrm{mM} / \mathrm{sec}$ to

236 see how it affects $\mathrm{Na}^{+}$fluctuations. We observed a strong effect of varying peak glial $\mathrm{K}^{+}$uptake on

237 the amplitude and frequency of $\mathrm{Na}^{+}$fluctuations $(\mathrm{p}>0.001)$. Overall, the amplitude and frequency

238 of $\mathrm{Na}^{+}$fluctuations decrease as we increase peak glial $\mathrm{K}^{+}$uptake (Figure 5C). 
The model predicts a higher propensity of neonatal brain for hyperexcitability.

241 Significant evidence shows that the neonatal brain is more hyperexcitable [28-31]. For

242 example, the frequency of seizure incidences is highest in the immature human brain $[15,32,33]$.

243 Critical periods where the animal brain is prone to seizures have also been well-documented [15].

244 Various epileptogenic agents and conditions, including an increase in $\left[\mathrm{K}^{+}\right]_{\mathrm{o}}$, result in sigmoid-

245 shaped age-dependence of seizure susceptibility in postnatal hippocampus [15, 34-36]. The

246 developmental changes in GABAergic function are suspected to play a key role in the change in

247 seizure threshold and the higher incidences of seizures in neonates [16, 37].

248 To test this hypothesis, we next investigate how excitatory GABAergic neurotransmission

249 affects the excitability of the network in response to different levels of $\left[\mathrm{K}^{+}\right]_{\mathrm{o}}$. In the model, we take

250 the average frequency of action potential (AP) generation (average number of spikes per minute

251 per neuron) of all excitatory neurons as a measure of the susceptibility of the network to

252 hyperexcited states such as seizures. As illustrated in Figure 6A, the overall AP frequency is

253 significantly larger in the network with inverted inhibition (representing the neonatal brain) than

254 the network with mature inhibition (representing a mature network). For all $\left[\mathrm{K}^{+}\right]_{\mathrm{o}}$ values tested,

255 the average AP frequency in the neonatal network is doubled that of mature network. Thus, our

256 simulation predicts that inverted inhibition strongly increases the excitability of neurons,

257 indicating a significantly lower threshold for hyperexcitability in neonates (Figure 6). Our

258 simulations also show that decreasing the radius of neurons or the $\mathrm{K}^{+}$uptake capacity of astrocytes

259 further increases the vulnerability of neonate brain to hyperactivity (not shown).

\section{Discussion}


Spontaneous neuronal and astrocytic activity is the hallmark of the developing brain and 263 drives cell differentiation, maturation, and network formation [1-9] [10, 11]. In the neonate

264 hippocampus, this activity is mostly attributed to the excitatory effect of GABAergic

265 neurotransmission [14]. While spontaneous activity has also been shown in cortical neuronal

266 networks, these appear to originate primarily from pace-maker cells in the piriform cortex, and are

267 driven by a separate mechanism involving both glutamate and GABA [38]. In contrast,

268 hippocampal early network oscillations stem solely from GABA released by interneurons.

269 Hippocampal interneurons constitute a diverse group of cells, including the fast-spiking inhibitory

270 neurons simulated in this study. These cells have previously been implicated in the generation of

271 early network activity in the hippocampus and cortex as the timing of their synapse formation

272 around pyramidal cells closely match that of the appearance of giant depolarizing potentials in the

273 neonatal brain. Additionally, the optogenetic blocking of their activity was shown to halt

274 spontaneous giant depolarizing potentials almost entirely [39].

275 The excitatory effect of GABA on neurons is related to the higher expression of the

$276 \mathrm{Na}^{+} / \mathrm{K}^{+} / \mathrm{Cl}^{-}$cotransporter as compared to the $\mathrm{K}^{+} / \mathrm{Cl}^{-}$cotransporter in the first week after birth. This

277 results in elevated intracellular $\mathrm{Cl}^{-}$, leading to an outwardly directed $\mathrm{Cl}^{-}$gradient [40-42], and in

278 an efflux of $\mathrm{Cl}^{-}$when $\mathrm{GABA}_{\mathrm{A}}$ receptor channels open, causing the post-synaptic neuron to

279 depolarize [18].

In this study, we report spontaneous, ultraslow fluctuations in the intracellular $\mathrm{Na}^{+}$

281 concentration of CA1 pyramidal neurons and astrocytes in tissue slices from mouse hippocampus,

282 recorded using ratiometric $\mathrm{Na}^{+}$imaging, thereby confirming our recent observations [5]. As

283 reported in the latter study, these spontaneous fluctuations are primarily present during the first

284 postnatal week and rapidly diminish afterwards. Unlike the giant depolarizing potentials (GDPs) 
285 and early network $\mathrm{Ca}^{2+}$ oscillations observed in the hippocampus previously $[2,7,12]$, the $\mathrm{Na}^{+}$

286 fluctuations reported here are not synchronous, involve only about a quarter of all pyramidal cells

287 recorded, are not significantly modulated by glutamatergic neurotransmission, and do not occur

288 with regular frequency. Furthermore, these fluctuations are extremely rare ( 2/hour), long-lasting

289 (each fluctuation lasting up to several minutes), and strongly attenuated by the application of TTX

290 to block VGSCs and application of inhibitors of GABAergic neurotransmission. A range of other

291 pharmacological blockers targeting various channels, receptors, co-transporters, or transporters did

292 not significantly affect these fluctuations (Figure 4 and [5]).

293 To investigate the origin of the spontaneous neuronal $\mathrm{Na}^{+}$fluctuations further, we

294 developed a detailed computational model that represents a hippocampal network, incorporating

295 the three main cell types (pyramidal cells, inhibitory neurons, and astrocytes) and ion concentration

296 dynamics in principal neurons and the extracellular space. In agreement with observations from

297 our experimental data presented here and the earlier experimental study [5], the computational

298 results suggest that voltage-gated $\mathrm{Na}^{+}$channels and the excitatory effect of GABAergic

299 neurotransmission play key roles in the generation of the ultraslow $\mathrm{Na}^{+}$fluctuations. Our

300 simulation results also reveal that these fluctuations occur at the individual neuronal level, are not

301 phase-locked, and are not strictly a network phenomenon, thereby confirming experimental results.

302 Moreover, the fluctuations are confined to intracellular $\mathrm{Na}^{+}$and are not observed in extracellular

$303 \mathrm{~K}^{+}$, further supporting the conclusion that these fluctuations are a local phenomenon.

Because synaptogenesis is ongoing during the first postnatal week, synapses across the

305 neuronal network display varying strengths. This means that while activity such as GDPs can

306 happen synchronously across populations, individual synapses will experience different levels of

$307 \mathrm{Na}^{+}$influx in response to action potentials. A neuron with a large number of strong synapses from 
an interneuron would therefore have a larger influx of $\mathrm{Na}^{+}$(considering the depolarizing inhibition in the neonate brain) than neurons with fewer, weaker connections. The pattern of connectivity and variations in GABA release between several interneurons could therefore explain the

311 unusually long, irregular, asynchronous fluctuations seen in individual neurons here, as they might

312 arise from the summation of inputs.

In addition to the outwardly directed $\mathrm{Cl}^{-}$gradient and the excitatory action of GABA, the

314 neonate forebrain in the first week after birth is in a constant state of flux where many functional

315 and morphological changes occur along with the differentiation and maturation of cells and the

316 cellular network $[7,12,13,19,43]$. Two of the most significant changes include the still ongoing

317 gliogenesis and astrocyte maturation [44-46]. Immature astrocytes have a reduced glial uptake

318 capacity for $\mathrm{K}^{+}$as well as for glutamate compared to the mature brain [19, 21, 47]. Furthermore,

319 the neonate brain exhibits an increased volume fraction of the ECS [23, 24, 48]. These factors

320 along with the morphological properties of cells, play key roles in ion concentration dynamics.

321 Indeed, we found the behavior of intracellular $\mathrm{Na}^{+}$fluctuations to be strongly reliant on neuronal

322 radius. However, the larger extra- to intracellular volume ratio appears to suppress $\mathrm{Na}^{+}$

323 fluctuations, suggesting that the larger relative ECS observed in neonates does not play a

324 significant mechanistic role in the generation of spontaneous activity. Our model also suggests that

325 increasing glial $\mathrm{K}^{+}$uptake capacity results in decreasing the amplitude and frequency of $\mathrm{Na}^{+}$

326 fluctuations in the individual neurons and thus may play a role in their suppression at later stages

327 of postnatal development.

328 Convincing evidence shows that the developing brain is more hyperexcitable. This is

329 supported by the significantly higher frequency of seizures in the neonatal brain $[15,32,33]$. The

330 higher occurrence of seizures is primarily attributed to the excitatory effect of GABA [49]. Based 
331 on the above analysis, we believe that the inability of astrocytes to effectively take up extracellular

$332 \mathrm{~K}^{+}$and morphological changes together with the inverted $\mathrm{Cl}^{-}$gradients leave the developing brain

333 more susceptible to hyperexcitability and epileptic seizures. As a proof of concept, we exposed

334 our model network to increasing concentrations of $\mathrm{K}^{+}$in the bath solution, similar to experimental

335 protocols used to generate epileptiform activity in brain slices. Indeed, we found that the network

336 representing the neonate brain is unable to cope with the elevated extracellular $\mathrm{K}^{+}$concentration

337 efficiently and exhibits hyperactivity as we increase bath $\mathrm{K}^{+}$. Decreasing the radius of neurons or

338 the $\mathrm{K}^{+}$uptake capacity of astrocytes further increases the vulnerability of neonate brain to

339 hyperactive behavior (not shown).

340 To summarize, our dual experiment-theory approach asserts that the ultraslow, long-

341 lasting, spontaneous intracellular $\mathrm{Na}^{+}$fluctuations observed in neonate brain are non-synchronous,

342 not coupled with fluctuations in extracellular $\mathrm{K}^{+}$, and only occur in a fraction of neurons (and

343 astrocytes, see Figure 1 and [5]). These fluctuations are most likely due to a combination of factors

344 with the excitatory GABAergic neurotransmission and action potential generation playing

345 dominant roles. In addition, other conditions in the neonate brain such as decreased $\mathrm{K}^{+}$uptake

346 capacity of astrocytes and morphological properties of neurons also play key roles. Furthermore,

347 glutamatergic and other pathways do not seem to make notable contributions to the $\mathrm{Na}^{+}$

348 fluctuations. The combination of factors described above also provides an environment in the

349 neonate brain that is conducive to hyperexcitability and seizure-like states. Thus, the experimental

350 and computational work presented here provides deep insights into this newly observed

351 phenomena and its possible link with hyperexcitability-related pathology in the developing brain.

\section{Materials and Methods}




\section{Experimental Methods}

\section{Relevant abbreviations and source of chemicals}

356 MPEP (2-Methyl-6-(phenylethynyl)pyridine) from Tocris

357 APV ((2R)-amino-5-phosphonovaleric acid; (2R)-amino-5-phosphonopentanoate) from Cayman 358 Chemical

359 NBQX (2,3-Dioxo-6-nitro-1,2,3,4-tetrahydrobenzo[f]quinoxaline-7-sulfonamide) from Tocris

360 CGP-55845 ((2S)-3-[[(1S)-1-(3,4-Dichlorophenyl)ethyl]amino-2-hydro

361 xypropyl](phenylmethyl)phosphinic acid hydrochloride) from Sigma-Aldrich

362 NNC-711 (1,2,5,6-Tetrahydro-1-[2-[[(diphenylmethylene)amino]oxy]ethyl]-3-

363 pyridinecarboxylic acid hydrochloride) from Tocris

364 SNAP-5114 (1-[2-[tris(4-methoxyphenyl)methoxy]ethyl]-(S)-3-piperidinecarboxylic acid) from

365 Sigma-Aldrich

366 Preparation of tissue slices

367 This study was carried out in accordance with the institutional guidelines of the Heinrich

368 Heine University Düsseldorf, as well as the European Community Council Directive

$369(2010 / 63 / \mathrm{EU})$. All experiments were communicated to and approved by the animal welfare office

370 of the animal care and use facility of the Heinrich Heine University Düsseldorf (institutional act

371 number: O52/05). In accordance with the German animal welfare act (Articles 4 and 7), no formal

372 additional approval for the post-mortem removal of brain tissue was necessary. In accordance with

373 the recommendations of the European Commission [50], juvenile mice were first anaesthetized

374 with $\mathrm{CO}_{2}$ before the animals were quickly decapitated, while animals younger than P10 received

375 no anesthetics. 
Acute brain slices with a thickness of $250 \mu \mathrm{m}$ were generated from mice (mus musculus,

384 Immediately after slicing, the slices were transferred to a water bath and incubated at $34^{\circ} \mathrm{C}$ with

for 15 minutes before the beginning, and subsequently throughout the measurements.

\section{$\underline{\text { Sodium Imaging }}$}

Slices were dye-loaded using the bolus injection technique (via use of a picospritzer 3,

391 Parker, Cologne, Germany). The sodium-sensitive ratiometric dye SBFI-AM (sodium-binding

392 benzofuran isophthalate-acetoxymethyl ester; Invitrogen, Schwerte, Germany) was used for

393 detection of $\mathrm{Na}^{+}$. SBFI was excited alternatingly at $340 \mathrm{~nm}\left(\mathrm{Na}^{+}\right.$-insensitive wavelength) and 380

$394 \mathrm{~nm}\left(\mathrm{Na}^{+}\right.$-sensitive wavelength) by a PolychromeV monochromator (Thermo Fisher Scientific,

395 Eindhoven, Netherlands). Emission was collected above $420 \mathrm{~nm}$ from defined regions of interest

396 (ROIs) drawn around cell somata using an upright microscope (Nikon Eclipse FN-1, Nikon,

397 Düsseldorf, Germany) equipped with a Fluor 40x/0.8W immersion objective (Nikon), and attached

398 to an ORCA FLASH 4.0 LT camera (Hamamatsu Photonics Deutschland GmbH, Herrsching, 
399 Germany). The imaging software used was NIS-elements AR v4.5 (Nikon, Düsseldorf, Germany).

400 For the identification of astrocytes [52], SR101 was excited at $575 \mathrm{~nm}$ and its emission collected

401 above $590 \mathrm{~nm}$.

402 Data analysis and statistics

403 For each ROI, a ratio of the sensitive and insensitive emissions was calculated and analyzed

404 using OriginPro 9.0 software (OriginLab Corporation, Northampton, MA, USA). Changes in

405 fluorescence ratio were converted to $\mathrm{mM} \mathrm{Na}^{+}$on the basis of an in situ calibration performed as

406 reported previously $[53,54]$. A signal was defined as being any change from the baseline, if $\mathrm{Na}^{+}$

407 levels exceeded 3 standard deviations of the baseline noise. Each series of experiments was

408 performed on at least four different animals, with 'n' reflecting the total number of individual cells

409 analyzed. Values from experiments mentioned in the text are presented as mean \pm standard error,

410 while values taken from models are presented as mean \pm standard deviation.

\section{Computational Methods}

The basic equations for the membrane potential of individual neurons, various ion

413 channels, and synaptic currents used in our model are adopted from Ref. [55]. The network

414 topology follows the scheme for hippocampus from the same work. As shown in Figure 7, the

415 network consists of pyramidal cells and fast-spiking interneurons with five to one ratio. The results

416 reported in this paper are from a network with 25 excitatory and 5 inhibitory neurons. Astrocytes

417 are not explicitly illustrated as cellular entities in Figure 7, but included in the model through their

418 ability to take up $\mathrm{K}^{+}$. Of note, increasing the network size does not change the conclusions from

419 the model (not shown). Each inhibitory neuron makes synaptic connections with 5 adjacent

420 postsynaptic pyramidal neurons (I-to-E synapses). Thus five excitatory and one inhibitory neurons

421 constitute one "domain". As shown in the "Results" section, we observed significant variability in 
422 the neuronal behavior. Approximately $25 \%$ of neurons tested exhibited $\mathrm{Na}^{+}$fluctuations.

423 Furthermore, the amplitude, duration, and frequency of the fluctuations varied over a wide range,

424 pointing towards a heterogeneity in the network topology. To incorporate the observed variability

425 in the neuronal behavior, the synaptic strengths vary randomly from one domain to another. For

426 inhibitory-to-inhibitory (I-to-I), excitatory-to-excitatory (E-to-E), and excitatory-to-inhibitory (E-

427 to-I) synapses, we consider all-to-all connections. However, restricting these synapses spatially

428 does not change the conclusions in the paper. We remark that if one wishes to use a network of a

429 different size with all-to-all connections, the maximum strength of these three types of synaptic

430 inputs will need to be scaled according to the network size.

431 The equations for individual cells are modified and extended to incorporate the dynamics

432 of various ion species in the intra- and extracellular spaces of the neurons using the formalism

433 previously developed in [27, 56-61]. The change in the membrane potential, $V_{m}$, for both excitatory

434 and inhibitory neurons in the network is controlled by various $\mathrm{Na}^{+}\left(\mathrm{I}_{\mathrm{Na}}\right), \mathrm{K}^{+}\left(\mathrm{I}_{\mathrm{K}}\right)$, and $\mathrm{Cl}^{-}\left(\mathrm{I}_{\mathrm{Cl}}\right)$

435 currents, current due to $\mathrm{Na}^{+} / \mathrm{K}^{+}$-ATPase $\left(I_{\text {pump }}\right)$, and random inputs from neurons that are not a part

436 of the network $\left(I_{\text {stoch }}^{E x}\right)$, and is given as

$$
\frac{d V_{m}^{E x, I n}}{d t}=I_{N a}^{E x, I n}+I_{K}^{E x, I n}+I_{C l}^{E x, I n}-I_{p u m p}^{E x, I n}+I_{s t o c h}^{E x / I n}
$$

The superscripts Ex and In correspond to excitatory and inhibitory neurons respectively.

439 The $\mathrm{Na}^{+}$and $\mathrm{K}^{+}$currents consist of active currents corresponding to fast sodium and delayed

440 rectifier potassium channels $\left(I_{N a}^{F} \& I_{K}^{D R}\right)$, passive leak currents $\left(I_{N a}^{l e a k} \& I_{K}^{l e a k}\right)$, and excitatory

441 synaptic currents $\left(I_{N a}^{s y n} \& I_{K}^{s y n}\right)$. The chloride currents consist of contributions from passive leak

442 current $\left(I_{C l}^{l e a k}\right)$ and inhibitory synaptic currents $\left(I_{C l}^{s y n}\right)$.

$$
I_{N a}^{E x, I n}=I_{N a}^{F}+I_{N a}^{l e a k}+I_{N a}^{s y n},
$$

$$
I_{K}^{E x, I n}=I_{K}^{D R}+I_{K}^{l e a k}+I_{K}^{s y n},
$$




$$
I_{C l}^{E x, I n}=I_{C l}^{l e a k}+I_{C l}^{s y n}
$$

The equations for active neuronal currents are given by the following equations,

$$
\begin{gathered}
I_{N a}^{F}=g_{N a} m_{\infty}^{3} h\left(V_{N a}-V_{m}\right), \\
I_{K}^{D R}=g_{k} n^{4}\left(V_{K}-V_{m}\right),
\end{gathered}
$$
maximum conductance of delayed rectifier $\mathrm{K}^{+}$, steady state gating variable for fast $\mathrm{Na}^{+}$activation, fast $\mathrm{Na}^{+}$inactivation variable, and delayed rectifier $\mathrm{K}^{+}$activation variable. As in [55], the gating variables and peak conductances for $I_{N a}^{F}, I_{K}^{D R}$, and leak currents for the pyramidal neurons in this study are based on the model of Ermentrout and Kopell [62], which is a reduction of a model due model in [64] and [65], which is a reduction of the multi-compartmental model described in Ref. [66]. These equations were originally chosen such that the model would result in the intrinsic

457 frequency as a function of stimulus strength observed in pyramidal cells and fast-spiking inhibitory 458 neurons respectively. The gating variables obey the following equations,

$$
x_{\infty}=\frac{\alpha_{x}}{\alpha_{x}+\beta_{x}}, \quad \tau_{x}=\frac{5}{\alpha_{x}+\beta_{x}}, \text { For } x=m, n, h
$$
are calculated using the equations below.

$$
\alpha_{n}=\frac{-0.01\left(V_{m}+34\right)}{\exp \left(-0.1\left(V_{m}+34\right)\right)-1}
$$

$$
\beta_{n}=0.125 \exp \left(-\frac{V_{m}+44}{80}\right)
$$

$$
\alpha_{h}=0.07 \exp \left(-\frac{V_{m}+58}{20}\right),
$$

$$
\beta_{h}=\frac{1}{\exp \left(-0.1\left(V_{m}+28\right)\right)+1}
$$




$$
\alpha_{m}=\frac{0.1\left(V_{m}+35\right)}{1-\exp \left(-\frac{V_{m}+35}{10}\right)}
$$

$$
\beta_{m}=4 \exp \left(-\frac{V_{m}+60}{10}\right)
$$

The leak currents are given by

$$
\begin{gathered}
I_{N a}^{\text {leak }}=g_{N a}^{\text {leak }}\left(V_{N a}-V_{m}\right), \\
I_{K}^{\text {leak }}=g_{K}^{\text {leak }}\left(V_{K}-V_{m}\right),
\end{gathered}
$$

where $V_{N a}, V_{K}$, and $V_{C l}$ are the reversal potentials for $\mathrm{Na}^{+}, \mathrm{K}^{+}$, and $\mathrm{Cl}^{-}$currents respectively and are

474 updated according to the instantaneous values of respective ion concentrations.

$476[55]$ and is given as

$$
I_{\text {stoch }}=-g_{\text {stoch }} S_{\text {stoch }} V_{m}
$$

Where $g_{\text {stoch }}$ represents the maximal conductance associated with the stochastic synaptic constant $\tau_{\text {stoch }}=100 \mathrm{~ms}$ during each time step $\Delta t$, that is

$$
S_{\text {stoch }}=S_{\text {stoch }} \exp \left(-\frac{\Delta t}{2 \times \tau_{\text {stoch }}}\right)
$$

At the end of each time step, $\mathrm{s}_{\text {stoch }}$ jumps to 1 with probability $\Delta \mathrm{t} \times f_{\text {stoch }} / 1000$, where $f_{\text {stoch }}$ 483 is the mean frequency of the stochastic inputs. These equations simulate the arrival of external 484 synaptic input pulses from the neurons that are not included in the network [55].

$$
I_{N a}^{s y n}=G_{A M P A / N M D A} S_{A M P A / N M D A}\left(V_{N a}-V_{m}\right)
$$

$$
I_{K}^{s y n}=G_{A M P A / N M D A} S_{A M P A / N M D A}\left(V_{K}-V_{m}\right),
$$




$$
I_{C l}^{s y n}=G_{G A B A} S_{G A B A}\left(V_{C l}-V_{m}\right)
$$
receptors. To incorporate the observed variability in neuronal behavior, we randomly select the maximal conductance value for I-to-E synapses inside a single domain from a Gaussian

494 distribution between 0.1 and $3.0 \mathrm{mS} / \mathrm{cm}^{2}$. In order to model the excitatory role of GABAergic 495 neurotransmission observed in neonate brain, we change the sign of $\mathrm{G}_{\mathrm{GABA}}$ from positive to negative. modeled as in [55]. That is

$$
\frac{d S}{d t}=\frac{1}{2}\left(1+\tanh \left(\frac{V_{m}}{4}\right)\right) \frac{1-S}{\tau_{R}}-\frac{S}{\tau_{D}}
$$

where $\tau_{R}$ and $\tau_{D}$ represent the rise and decay time constants for synaptic signals. The reversal potentials used in the above equations are calculated using the Nernst equilibrium potential equations, i.e.

Where $\left[\mathrm{K}^{+}\right]_{\mathrm{o} / \mathrm{i}},\left[\mathrm{Na}^{+}\right]_{\mathrm{o} / \mathrm{i}}$, and $\left[\mathrm{Cl}^{-}\right]_{\mathrm{o} / \mathrm{i}}$ represent the concentration of $\mathrm{Na}^{+}, \mathrm{K}^{+}$, and $\mathrm{Cl}^{-}$outside and inside the neuron respectively. We consider the ECS as a separate compartment surrounding

508 each cell, having a volume of approximately $15 \%$ of the intracellular space (ICS) in the 509 hippocampus of adult brain $[25,26]$ and $\sim 40 \%$ of the ICS in neonates $[23,24]$. Each neuron 510 exchanges ions with its ECS compartment through active and passive currents, and the $\mathrm{Na}^{+} / \mathrm{K}^{+}-$ 
511 ATPase. The ECS compartment can also exchange $\mathrm{K}^{+}$with the glial compartment, perfusion

512 solution (or vasculature in intact brain), and the ECS compartments of the nearby neurons [67-69].

513 The change in $\left[\mathrm{K}^{+}\right]_{o}$ is a function of $I_{K}, I_{\text {pump }}$, uptake by glia surrounding the neuron $\left(I_{\text {glia }}\right)$,

514 diffusion between the neuron and bath perfusate $\left(I_{\text {diffl }}\right)$, and lateral diffusion between adjacent

515 neurons $\left(\mathrm{I}_{\mathrm{diff} 2}\right)$.

$$
\frac{d\left[K^{+}\right]_{o}}{d t}=-\gamma \beta I_{N a}-2 \gamma \beta I_{p u m p}+I_{g l i a}-I_{d i f f 1}+I_{d i f f 2}
$$

Where $\beta$ is the ratio of ICS to ECS. We set $\beta=7$ in adult and 2.5 in neonates to incorporate

518 the larger ECS $(\sim 15 \%$ and $\sim 40 \%$ of the ICS in adults and neonates respectively) observed in neonates $[23,24]$. To see how the relative volume of ECS affects the behavior of spontaneous $\mathrm{Na}^{+}$

520 fluctuations, we vary $\beta$ over a wide range in some simulations of neonate network. We remark that 521 using $\beta=2.5$ in the network representing the adult brain (mature inhibition) didn't cause 522 spontaneous $\mathrm{Na}^{+}$fluctuations (not shown). $\gamma=3 \times 10^{4} /\left(F \times r_{i n}\right)$ is the conversion factor from 523 current units to flux units, where $F$ and $r_{i n}$ are the Faraday's constant and radius of the neuron, 524 respectively. The factor 2 in front of $I_{\text {pump }}$ is due to the fact that the $\mathrm{Na}^{+} / \mathrm{K}^{+}$pump extrudes two $\mathrm{K}^{+}$ 525 in exchange for three $\mathrm{Na}^{+}$.

526 The rate of change of $\left[\mathrm{Na}^{+}\right]_{i}$ is controlled by $I_{N a}$ and $I_{p u m p}[27]$, that is

$$
\frac{d\left[N a^{+}\right]_{i}}{d t}=\gamma I_{N a}-3 \gamma I_{p u m p} .
$$

The equations modeling $I_{\text {pump }}, I_{\text {glia }}$, and $I_{\text {diff } 1}$ are given as

$$
\begin{gathered}
I_{\text {pump }}=\frac{\rho}{1+\exp \left(\left(25-\left[\mathrm{Na}^{+}\right]_{i}\right) / 3\right)} \frac{1}{1.0+\exp \left(5.5-\left[\mathrm{K}^{+}\right]_{o}\right)} . \\
I_{\text {diff } 1}=\epsilon_{K}\left(\left[\mathrm{~K}^{+}\right]_{o}-\left[K^{+}\right]_{\text {bath }}\right), \\
I_{\text {glia }}=\frac{G_{\text {glia }}}{1+\exp \left(10\left(3-\left[\mathrm{K}^{+}\right]_{o}\right)\right)} .
\end{gathered}
$$



tissue $\left(\left[\mathrm{O}_{2}\right]\right)$ or perfusion solution $[70]$, that is

$$
\rho=\frac{\rho_{\max }}{1+\exp \left(\frac{20-\left[O_{2}\right]}{3}\right)}
$$

535 and $\rho_{\max }, G_{\text {glia }}, \epsilon_{k}$, and $\left[K^{+}\right]_{\text {bath }}$ represent the maximum $\mathrm{Na}^{+} / \mathrm{K}^{+}$pump strength, maximum glial $K^{+}$

536 uptake, constant for $\mathrm{K}^{+}$diffusion to vasculature or bath solution, and $\mathrm{K}^{+}$concentration in the

537 perfusion solution respectively. The change in oxygen concentration is given by the following rate 538 equation [70].

$$
\frac{d\left[O_{2}\right]_{o}}{d t}-\alpha I_{\text {pump }}+\epsilon_{0}\left(\left[O_{2}\right]_{\text {bath }}-\left[O_{2}\right]_{o}\right)
$$

542 is the diffusion rate constant for oxygen from bath solution to the neuron. We also incorporate 543 lateral diffusion of $\mathrm{K}^{+}\left(\mathrm{I}_{\mathrm{diff} 2}\right)$ between adjacent neurons where the extracellular $\mathrm{K}^{+}$of each neuron

544 in the excitatory layer diffuses to/from the nearest neighbors in the same layer and one nearest

545 neuron in the inhibitory layer. That is,

$$
I_{d i f f 2}=\frac{D_{k}}{d x^{2}}\left(\left[K^{+}\right]_{o, i+1}^{E x}+\left[K^{+}\right]_{o, i-1}^{E x}+\left[K^{+}\right]_{o, i}^{I n}-3\left[K^{+}\right]_{o, i}^{E x}\right)
$$

547 where the subscript $i$ indicates the index of the neuron with which the exchange occurs, $D_{k}$ is the

548 diffusion coefficient of $\mathrm{K}^{+}$, and $d x$ represents the separation between neighboring cells. The

549 diffusion of $\mathrm{K}^{+}$in the inhibitory layer is modified so that each inhibitory neuron exchanges $\mathrm{K}^{+}$

550 with the two nearest neighbors in the same layer and five nearest neighbors in the excitatory layer.

551 The separation between neighboring neurons in the inhibitory layer is five times that of 552 neighboring neurons in the excitatory layer. 
To simplify the formalism, $\left[\mathrm{K}^{+}\right]_{i}$ and $\left[\mathrm{Na}^{+}\right]_{o}$ are linked to $\left[\mathrm{Na}^{+}\right]_{i}$ as previously described

$554[27,56,57,71,72]$.

558 respectively.

The number 150 in the above equation represents the concentration of impermeable

562 cations. The values of various parameters used in the model are given in Table 1.

\section{Numerical Methods}

The rate equations were solved in Fortran 90 using the midpoint method, with a time step

565 of $0.02 \mathrm{~ms}$. The statistical analysis of the data obtained from simulations is performed in Matlab.

566 Codes reproducing key results are available upon request from authors. Significance was

567 determined using students t-tests $(\mathrm{p}>0.001: * * *)$.

\section{Acknowledgements}

570 This works was supported by NIH through grant number R01AG053988 (GU), the Deutsche

571 Forschungsgemeinschaft through grant number SPP1757:Ro2327/8-2 (CRR), and a start-up fund 572 of the SPP1757 (LF). 


\section{References}

576 1. Spitzer NC. Electrical activity in early neuronal development. Nature. $577 \quad 2006 ; 444(7120): 707-12$.

578 2. Garaschuk O, Linn J, Eilers J, Konnerth A. Large-scale oscillatory calcium waves in the

579 immature cortex. Nature neuroscience. 2000;3(5):452-9.

580 3. Leinekugel X, Medina I, Khalilov I, Ben-Ari Y, Khazipov R. Ca2+ oscillations mediated

581 by the synergistic excitatory actions of GABAA and NMDA receptors in the neonatal

582 hippocampus. Neuron. 1997;18(2):243-55.

583 4. Spitzer NC. Spontaneous Ca2+ spikes and waves in embryonic neurons: signaling systems 584 for differentiation. Trends in neurosciences. 1994;17(3):115-8.

585 5. Felix L, Ziemens D, Seifert G, Rose CR. Spontaneous Ultraslow Na+ Fluctuations in the 586 Neonatal Mouse Brain. Cells. 2020;9(1):102.

587 6. Katz LC, Shatz CJ. Synaptic activity and the construction of cortical circuits. Science. $588 \quad 1996 ; 274(5290): 1133-8$.

589 7. Garaschuk O, Hanse E, Konnerth A. Developmental profile and synaptic origin of early 590 network oscillations in the CA1 region of rat neonatal hippocampus. The Journal of physiology. $591 \quad 1998 ; 507(1): 219-36$.

592 8. Ben-Ari Y, Cherubini E, Corradetti R, Gaiarsa J. Giant synaptic potentials in immature rat 593 CA3 hippocampal neurones. The Journal of physiology. 1989;416(1):303-25.

594 9. Penn AA, Riquelme PA, Feller MB, Shatz CJ. Competition in retinogeniculate patterning 595 driven by spontaneous activity. Science. 1998;279(5359):2108-12. 
596 10. Luhmann HJ, Sinning A, Yang J-W, Reyes-Puerta V, Stüttgen MC, Kirischuk S, et al.

597 Spontaneous neuronal activity in developing neocortical networks: from single cells to large-scale

598 interactions. Frontiers in neural circuits. 2016;10:40.

599 11. Griguoli M, Cherubini E. Early correlated network activity in the hippocampus: its putative

600 role in shaping neuronal circuits. Frontiers in cellular neuroscience. 2017;11:255.

601 12. Ben-Ari Y, Khazipov R, Leinekugel X, Caillard O, Gaiarsa J-L. GABAA, NMDA and 602 AMPA receptors: a developmentally regulatedmenage a trois'. Trends in neurosciences. $603 \quad 1997 ; 20(11): 523-9$.

604 13. Lohmann C, Kessels HW. The developmental stages of synaptic plasticity. The Journal of 605 physiology. 2014;592(1):13-31.

606 14. Cherubini E, Gaiarsa JL, Ben-Ari Y. GABA: an excitatory transmitter in early postnatal 607 life. Trends in neurosciences. 1991;14(12):515-9.

608 15. Ben-Ari Y, Gaiarsa J-L, Tyzio R, Khazipov R. GABA: a pioneer transmitter that excites 609 immature neurons and generates primitive oscillations. Physiological reviews. 2007;87(4):121561084.

611 16. Ben-Ari Y, Holmes GL. The multiple facets of $\gamma$-aminobutyric acid dysfunction in 612 epilepsy. Current opinion in neurology. 2005;18(2):141-5.

613 17. Rivera C, Voipio J, Kaila K. Two developmental switches in GABAergic signalling: the $614 \mathrm{~K}+-\mathrm{Cl}-$ cotransporter $\mathrm{KCC} 2$ and carbonic anhydrase CAVII. The Journal of physiology. $615 \quad 2005 ; 562(1): 27-36$.

616 18. Kirmse K, Kummer M, Kovalchuk Y, Witte OW, Garaschuk O, Holthoff K. GABA 617 depolarizes immature neurons and inhibits network activity in the neonatal neocortex in vivo. 618 Nature communications. 2015;6(1):1-13. 
619 19. Larsen BR, Stoica A, MacAulay N. Developmental maturation of activity-induced K+ and $620 \mathrm{pH}$ transients and the associated extracellular space dynamics in the rat hippocampus. The Journal 621 of Physiology. 2019;597(2):583-97.

622 20. MacAulay N. Molecular mechanisms of K+ clearance and extracellular space shrinkage-

623 Glia cells as the stars. Glia. 2020.

624 21. Felix L, Stephan J, Rose CR. Astrocytes of the early postnatal brain. European Journal of 625 Neuroscience. 2020;in press.

626 22. Safiulina VF, Zacchi P, Taglialatela M, Yaari Y, Cherubini E. Low expression of Kv7/M 627 channels facilitates intrinsic and network bursting in the developing rat hippocampus. The Journal 628 of physiology. 2008;586(22):5437-53.

629 23. Lehmenkühler A, Syková E, Svoboda J, Zilles K, Nicholson C. Extracellular space 630 parameters in the rat neocortex and subcortical white matter during postnatal development 631 determined by diffusion analysis. Neuroscience. 1993;55(2):339-51.

632 24. Nicholson C, Hrabětová S. Brain extracellular space: the final frontier of neuroscience.

633 Biophysical journal. 2017;113(10):2133-42.

634 25. Zuzana S, Syková E. Diffusion heterogeneity and anisotropy in rat hippocampus.

635 Neuroreport. 1998;9(7):1299-304.

636 26. McBain CJ, Traynelis SF, Dingledine R. Regional variation of extracellular space in the 637 hippocampus. Science. 1990;249(4969):674-7.

638 27. Cressman JR, Ullah G, Ziburkus J, Schiff SJ, Barreto E. The influence of sodium and 639 potassium dynamics on excitability, seizures, and the stability of persistent states: I. Single neuron 640 dynamics. Journal of computational neuroscience. 2009;26(2):159-70. 
641 28. Panayiotopoulos C. Neonatal seizures and neonatal syndromes. The Epilepsies: Seizures, 642 Syndromes and Management: Bladon Medical Publishing; 2005.

643 29. Zanelli S, Rajasekaran K, Grosenbaugh D, Kapur J. Increased excitability and excitatory 644 synaptic transmission during in vitro ischemia in the neonatal mouse hippocampus. Neuroscience. $645 \quad 2015 ; 310: 279-89$.

646 30. Van Zundert B, Peuscher MH, Hynynen M, Chen A, Neve RL, Brown RH, et al. Neonatal 647 neuronal circuitry shows hyperexcitable disturbance in a mouse model of the adult-onset 648 neurodegenerative disease amyotrophic lateral sclerosis. Journal of Neuroscience. $649 \quad 2008 ; 28(43): 10864-74$.

650 31. Bender RA, Baram TZ. Epileptogenesis in the developing brain: what can we learn from 651 animal models? Epilepsia. 2007;48:2-6.

652 32. Hauser WA. Seizure disorders: the changes with age. Epilepsia. 1992;33:6-14.

653 33. Hauser WA. The prevalence and incidence of convulsive disorders in children. Epilepsia. 654 1994;35:S1-S6.

655 34. Dzhala VI, Staley KJ. Excitatory actions of endogenously released GABA contribute to 656 initiation of ictal epileptiform activity in the developing hippocampus. Journal of Neuroscience. $657 \quad 2003 ; 23(5): 1840-6$.

658 35. Isaev D, Isaeva E, Khazipov R, Holmes GL. Anticonvulsant action of GABA in the high 659 potassium-low magnesium model of ictogenesis in the neonatal rat hippocampus in vivo and in 660 vitro. Journal of neurophysiology. 2005;94(4):2987-92.

661 36. Khazipov R, Khalilov I, Tyzio R, Morozova E, Ben-Ari Y, Holmes GL. Developmental 662 changes in GABAergic actions and seizure susceptibility in the rat hippocampus. European Journal 663 of Neuroscience. 2004;19(3):590-600. 
664 37. Ben-Ari Y, Holmes GL. Effects of seizures on developmental processes in the immature 665 brain. The Lancet Neurology. 2006;5(12):1055-63.

666 38. Barger Z, Easton CR, Neuzil KE, Moody WJ. Early network activity propagates

667 bidirectionally between hippocampus and cortex. Developmental neurobiology. 2016;76(6):66166872.

669 39. Pelkey KA, Chittajallu R, Craig MT, Tricoire L, Wester JC, McBain CJ. Hippocampal

670 GABAergic inhibitory interneurons. Physiological reviews. 2017;97(4):1619-747.

671 40. Rivera C, Voipio J, Payne JA, Ruusuvuori E, Lahtinen H, Lamsa K, et al. The K+/Cl- co672 transporter KCC2 renders GABA hyperpolarizing during neuronal maturation. Nature. $673 \quad 1999 ; 397(6716): 251-5$.

674 41. Achilles K, Okabe A, Ikeda M, Shimizu-Okabe C, Yamada J, Fukuda A, et al. Kinetic 675 properties of $\mathrm{Cl}-$ uptake mediated by $\mathrm{Na}+$-dependent $\mathrm{K}+-2 \mathrm{Cl}-$ cotransport in immature rat 676 neocortical neurons. Journal of Neuroscience. 2007;27(32):8616-27.

677 42. Kaila K, Price TJ, Payne JA, Puskarjov M, Voipio J. Cation-chloride cotransporters in 678 neuronal development, plasticity and disease. Nature Reviews Neuroscience. 2014;15(10):637.

679 43. Bordey A, Sontheimer H. Postnatal development of ionic currents in rat hippocampal 680 astrocytes in situ. Journal of Neurophysiology. 1997;78(1):461-77.

681 44. Kriegstein A, Alvarez-Buylla A. The glial nature of embryonic and adult neural stem cells. 682 Annual review of neuroscience. 2009;32:149-84.

683 45. Wang DD, Bordey A. The astrocyte odyssey. Progress in neurobiology. 2008;86(4):34268467.

685 46. Privat A. Postnatal gliogenesis in the mammalian brain. Int Rev Cytol. 1975;40(28):1-323. 
47. Schreiner AE, Durry S, Aida T, Stock MC, Rüther U, Tanaka K, et al. Laminar and subcellular heterogeneity of GLAST and GLT-1 immunoreactivity in the developing postnatal mouse hippocampus. Journal of Comparative Neurology. 2014;522(1):204-24.

689 48. Syková E, Nicholson C. Diffusion in brain extracellular space. Physiological reviews. $690 \quad 2008 ; 88(4): 1277-340$.

691 49. Khalilov I, Le Van Quyen M, Gozlan H, Ben-Ari Y. Epileptogenic actions of GABA and

692 fast oscillations in the developing hippocampus. Neuron. 2005;48(5):787-96.

693 50. Close B, Banister K, Baumans V, Bernoth EM, Bromage N, Bunyan J, et al.

694 Recommendations for euthanasia of experimental animals: Part 2. DGXT of the European

695 Commission. Laboratory animals. 1997;31(1):1-32. Epub 1997/01/01. doi: 10.1258/002367797780600297. PubMed PMID: 9121105.

697 51. Gerkau NJ, Lerchundi R, Nelson JS, Lantermann M, Meyer J, Hirrlinger J, et al. Relation 698 between activity-induced intracellular sodium transients and ATP dynamics in mouse 699 hippocampal neurons. The Journal of physiology. 2019;597(23):5687-705.

700 52. Kafitz KW, Meier SD, Stephan J, Rose CR. Developmental profile and properties of 701 sulforhodamine 101-Labeled glial cells in acute brain slices of rat hippocampus. Journal of 702 neuroscience methods. 2008;169(1):84-92.

703 53. Langer J, Gerkau NJ, Derouiche A, Kleinhans C, Moshrefi-Ravasdjani B, Fredrich M, et 704 al. Rapid sodium signaling couples glutamate uptake to breakdown of ATP in perivascular 705 astrocyte endfeet. Glia. 2017;65(2):293-308.

706 54. Langer J, Rose CR. Synaptically induced sodium signals in hippocampal astrocytes in situ. 707 The Journal of physiology. 2009;587(24):5859-77. 
708 55. Kopell N, Börgers C, Pervouchine D, Malerba P, Tort A. Gamma and theta rhythms in

709 biophysical models of hippocampal circuits. Hippocampal microcircuits: Springer; 2010. p. 423-

71057.

711 56. Ullah G, Schiff SJ. Assimilating seizure dynamics. PLoS computational biology.

$712 \quad 2010 ; 6(5): \mathrm{e} 1000776$.

713 57. Ullah G, Wei Y, Dahlem MA, Wechselberger M, Schiff SJ. The role of cell volume in the

714 dynamics of seizure, spreading depression, and anoxic depolarization. PLoS computational

715 biology. 2015;11(8):e1004414.

716 58. Krishnan GP, González OC, Bazhenov M. Origin of slow spontaneous resting-state

717 neuronal fluctuations in brain networks. Proceedings of the National Academy of Sciences.

$718 \quad 2018 ; 115(26): 6858-63$.

719 59. Somjen G, Kager H, Wadman W. Computer simulations of neuron-glia interactions

720 mediated by ion flux. Journal of computational neuroscience. 2008;25(2):349-65.

721 60. Huebel N, Ullah G. Anions govern cell volume: a case study of relative astrocytic and

722 neuronal swelling in spreading depolarization. PloS one. 2016;11(3).

723 61. Hübel N, Hosseini-Zare MS, Žiburkus J, Ullah G. The role of glutamate in neuronal ion 724 homeostasis: A case study of spreading depolarization. PLoS computational biology. $725 \quad 2017 ; 13(10): \mathrm{e} 1005804$.

726 62. Ermentrout GB, Kopell N. Fine structure of neural spiking and synchronization in the 727 presence of conduction delays. Proceedings of the National Academy of Sciences. 728 1998;95(3):1259-64.

729 63. Traub RD, Miles R. Neuronal networks of the hippocampus: Cambridge University Press; 7301991. 
731 64. Tort AB, Rotstein HG, Dugladze T, Gloveli T, Kopell NJ. On the formation of gamma-

732 coherent cell assemblies by oriens lacunosum-moleculare interneurons in the hippocampus.

733 Proceedings of the National Academy of Sciences. 2007;104(33):13490-5.

734 65. Wang X-J, Buzsáki G. Gamma oscillation by synaptic inhibition in a hippocampal 735 interneuronal network model. Journal of neuroscience. 1996;16(20):6402-13.

736 66. Saraga F, Wu C, Zhang L, Skinner F. Active dendrites and spike propagation in 737 multicompartment models of oriens-lacunosum/moleculare hippocampal interneurons. The 738 Journal of physiology. 2003;552(3):673-89.

739 67. Krishnan GP, Bazhenov M. Ionic dynamics mediate spontaneous termination of seizures 740 and postictal depression state. Journal of Neuroscience. 2011;31(24):8870-82.

741 68. Fröhlich F, Bazhenov M, Iragui-Madoz V, Sejnowski TJ. Potassium dynamics in the 742 epileptic cortex: new insights on an old topic. The Neuroscientist. 2008;14(5):422-33.

743 69. Ullah G, Cressman Jr JR, Barreto E, Schiff SJ. The influence of sodium and potassium 744 dynamics on excitability, seizures, and the stability of persistent states: II. Network and glial 745 dynamics. Journal of computational neuroscience. 2009;26(2):171-83.

746 70. Wei Y, Ullah G, Ingram J, Schiff SJ. Oxygen and seizure dynamics: II. Computational 747 modeling. Journal of neurophysiology. 2014;112(2):213-23.

748 71. Wei Y, Ullah G, Schiff SJ. Unification of neuronal spikes, seizures, and spreading 749 depression. Journal of Neuroscience. 2014;34(35):11733-43.

750 72. Hübel N, Andrew RD, Ullah G. Large extracellular space leads to neuronal susceptibility 751 to ischemic injury in a $\mathrm{Na}+\mathrm{K}+$ pumps-dependent manner. Journal of computational neuroscience. $752 \quad 2016 ; 40(2): 177-92$. 


\section{Figures and Legends}

A1.
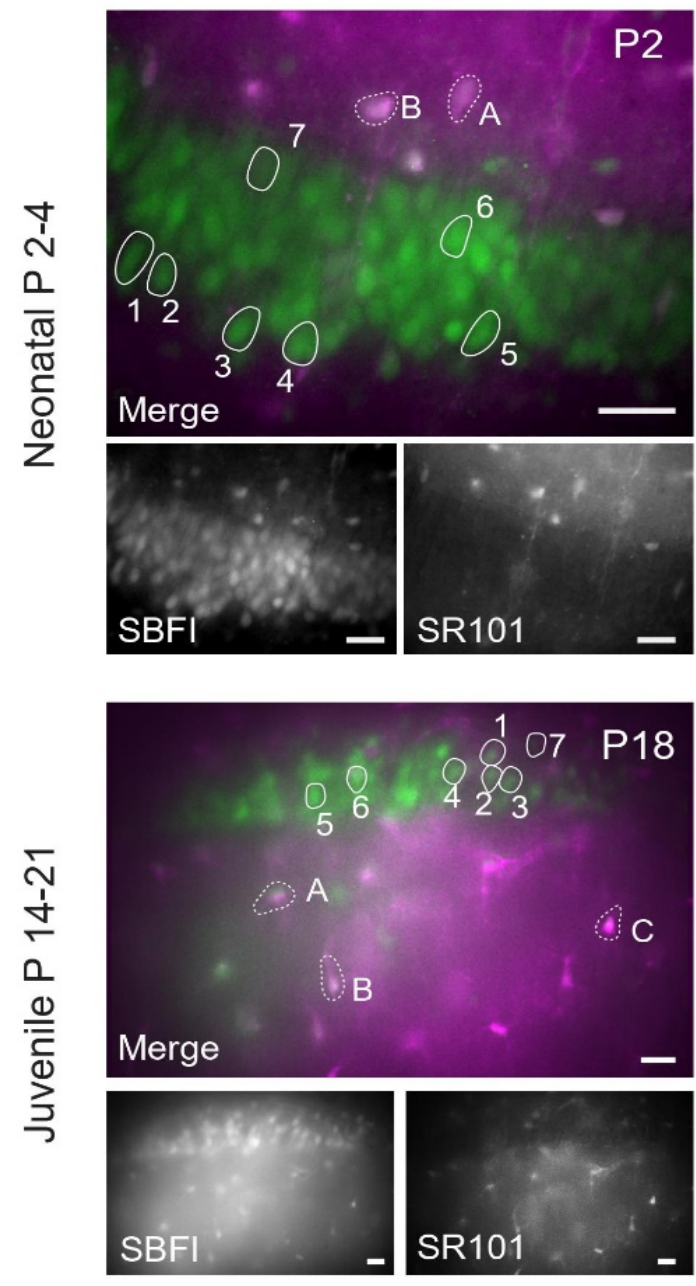

B.

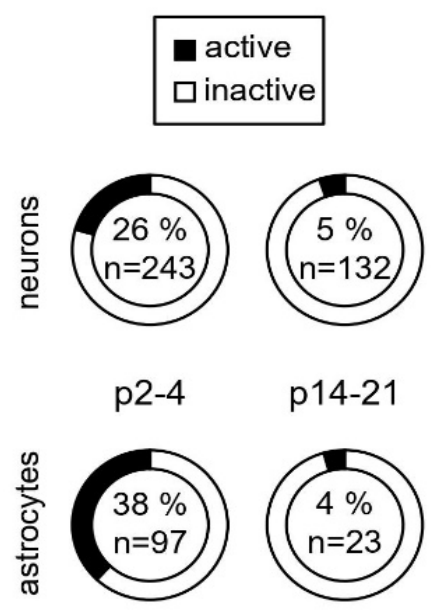

A2.

neurons

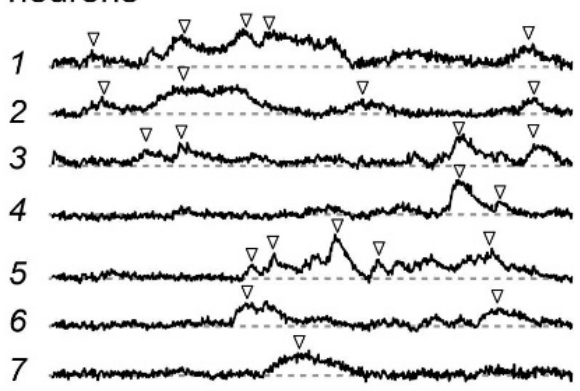

astrocytes

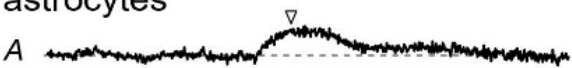
$B$
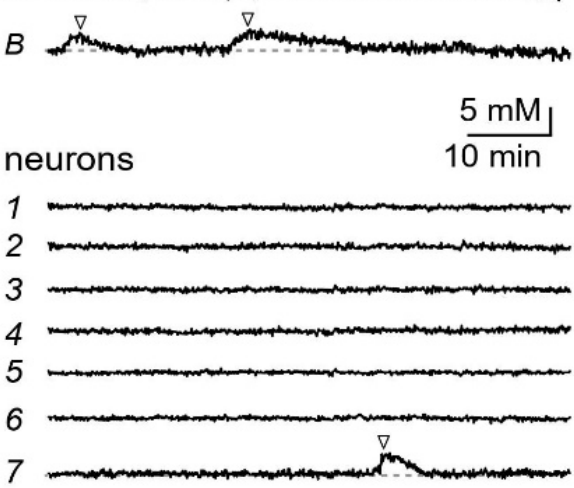
astrocytes

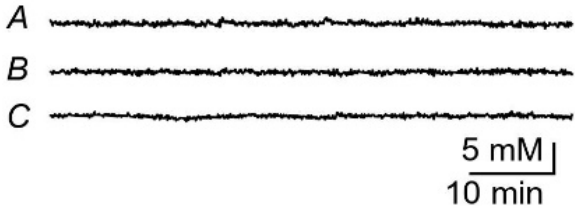

C.

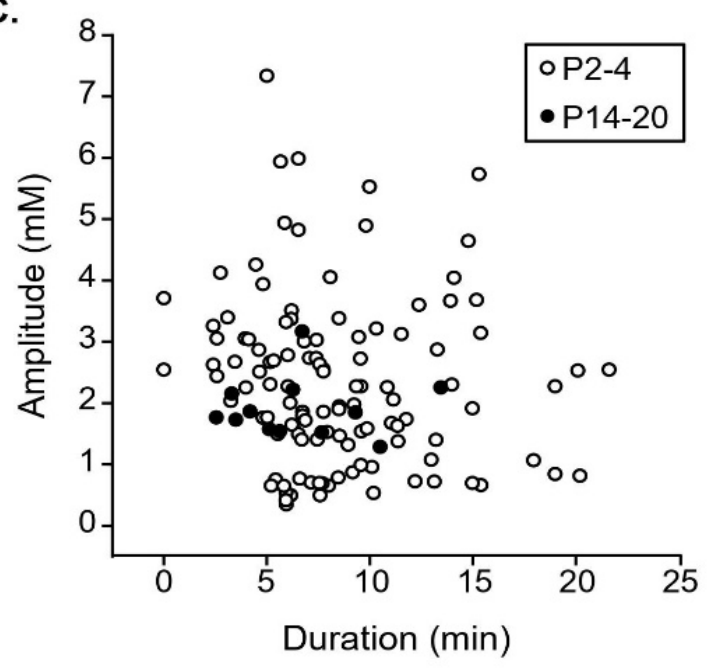


756 Figure 1. In situ experiments. (A1) Images showing representative stainings in the CA1 region of

757 the neonatal (P4; upper images) and juvenile (P18; lower images) hippocampus. In the merge,

758 SBFI is shown in green and SR101 in magenta. ROIs representing cell bodies of neurons and

759 astrocytes are labeled with numbers and letters, respectively. Scale bars: $20 \mu \mathrm{m}$. (A2) $\mathrm{Na}^{+}$

760 fluctuations in the ROIs as depicted in (A1). (B) The percentage of pyramidal neurons and

761 astrocytes showing activity for each age group and the total number of cells measured. (C) Scatter

762 plot showing the peak amplitude and duration of neuronal fluctuations within the two indicated

763 age groups. 


\section{A. Simulation}

Inverted Inhibition

Normal Inhibition

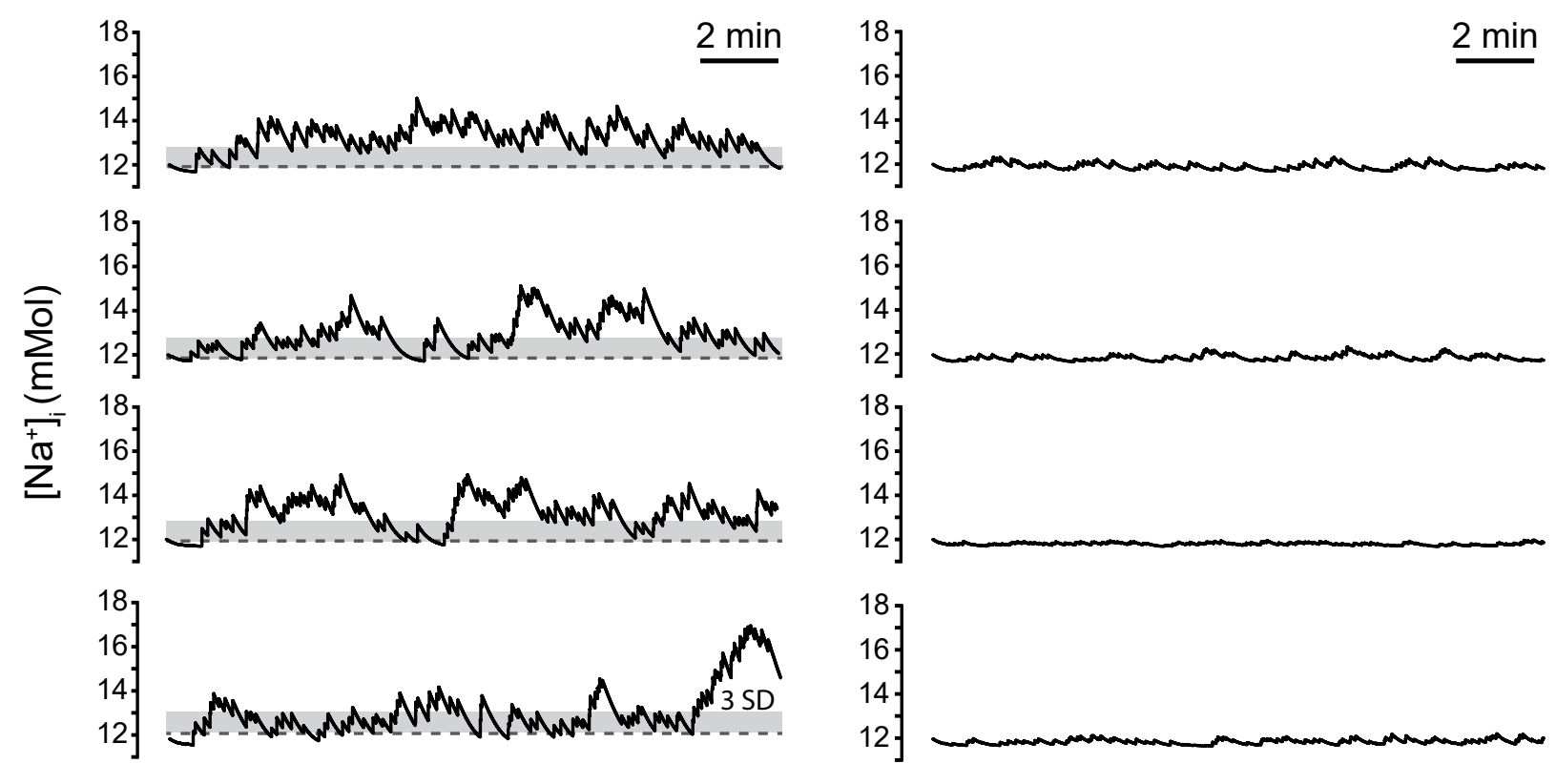

B. Experiment

Neonatal (P2-4)

Juvenile (P14-21)
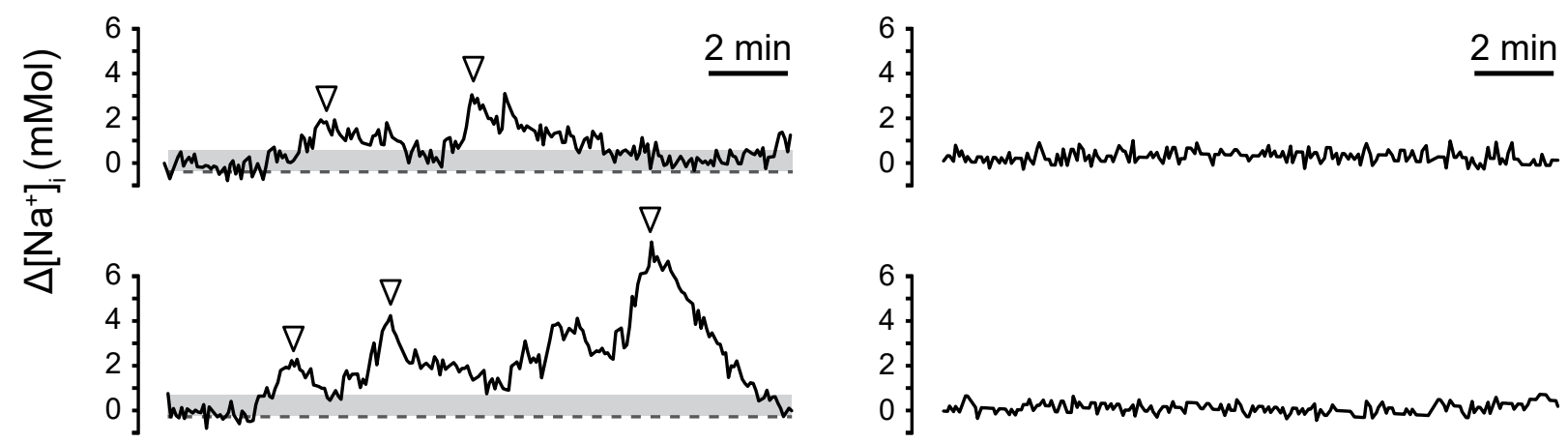

Figure 2: Simulated spontaneous activity in 4 example neurons with excitatory GABAergic neurotransmission representing neonatal hippocampus (A, left) and mature inhibition representing

767 juvenile hippocampus (A, right). Grey bar indicates three times the average standard deviation in

768 experimental traces upwards of the mean. (B) Experimental data, showing excerpts from example 769 measurements shown in Figure 1, both from neonatal neurons (P2-4, left; cell 3- upper; cell 5- 
bioRxiv preprint doi: https://doi.org/10.1101/2020.05.29.123026; this version posted May 29, 2020. The copyright holder for this preprint (which

was not certified by peer review) is the author/funder, who has granted bioRxiv a license to display the preprint in perpetuity. It is made available under aCC-BY 4.0 International license.

770 lower), and juvenile neurons (P14-21, right; cell 1- upper; cell 2- lower). Traces show changes in

771 intracellular $\mathrm{Na}^{+}$concentration over 17 minutes, a time course directly comparable to (A).

772 


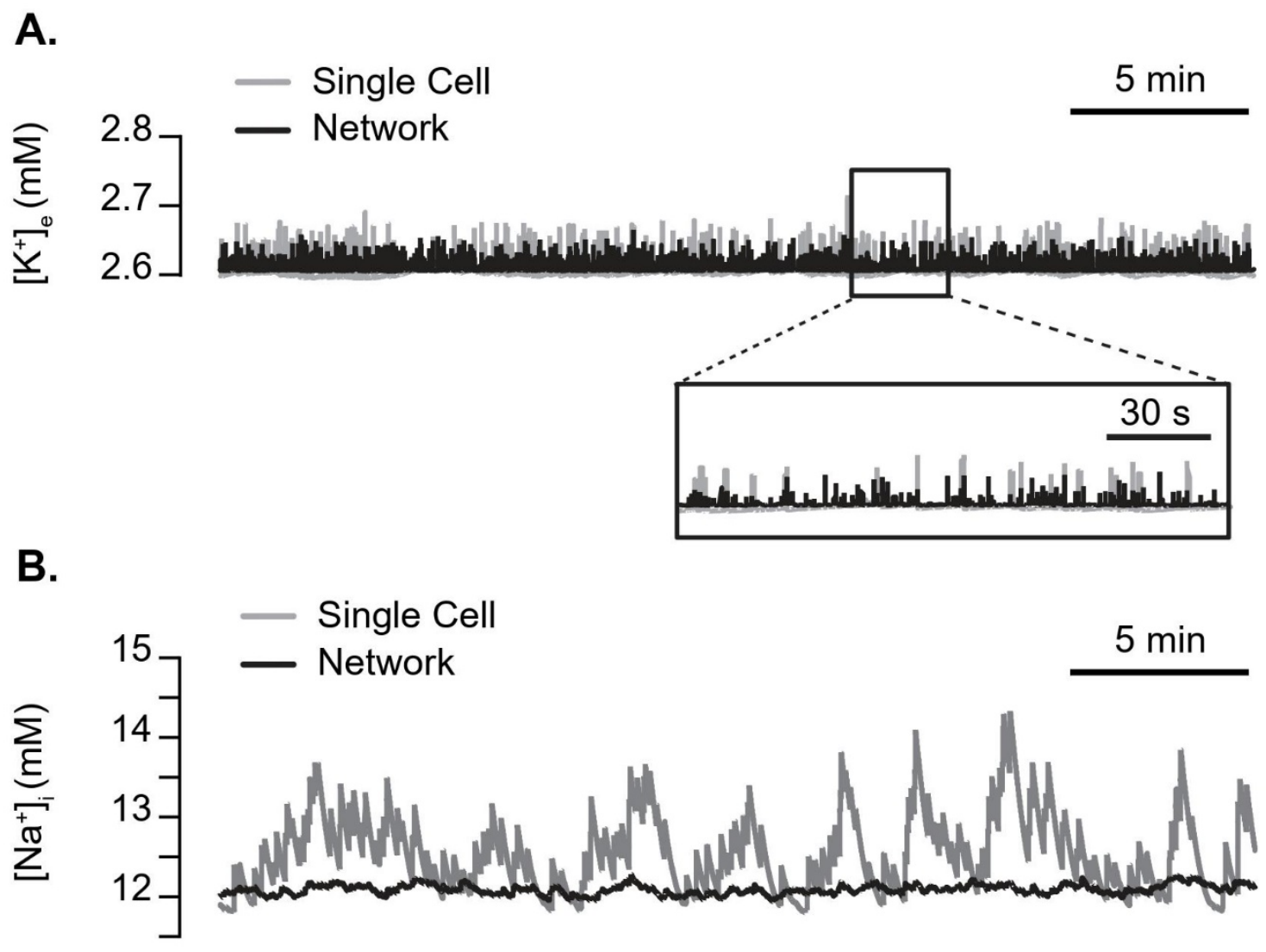

775 Figure 3: Simulated spontaneous fluctuations in intracellular $\mathrm{Na}^{+}\left(\left[\mathrm{Na}^{+}\right]_{\mathrm{i}}\right)$ are not coupled with

776 significant fluctuations in extracellular $\mathrm{K}^{+}\left(\left[\mathrm{K}^{+}\right]_{\mathrm{o}}\right) \cdot\left[\mathrm{K}^{+}\right]_{\mathrm{o}}(\mathrm{A})$ and $\left[\mathrm{Na}^{+}\right]_{\mathrm{i}}(\mathrm{B})$ time traces from a

777 randomly selected excitatory neuron (gray) and averaged over the entire excitatory network 778 (black). 


\section{A. Experimental Pharmacology}

781

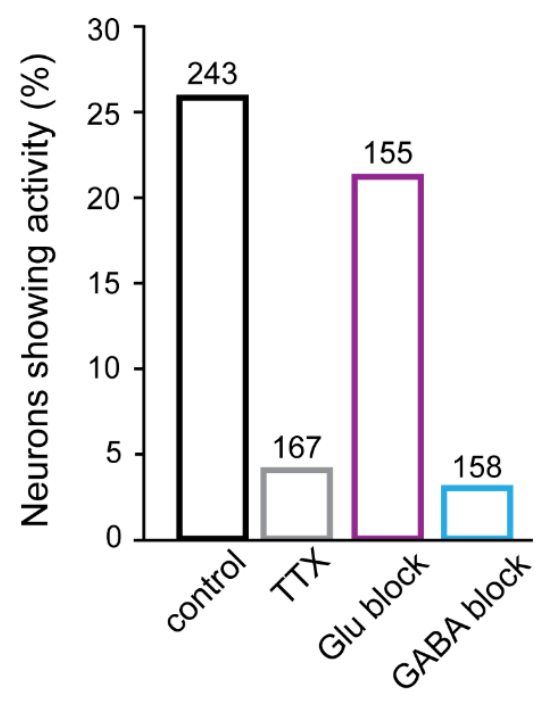

\section{B. Simulated Pharmacology}
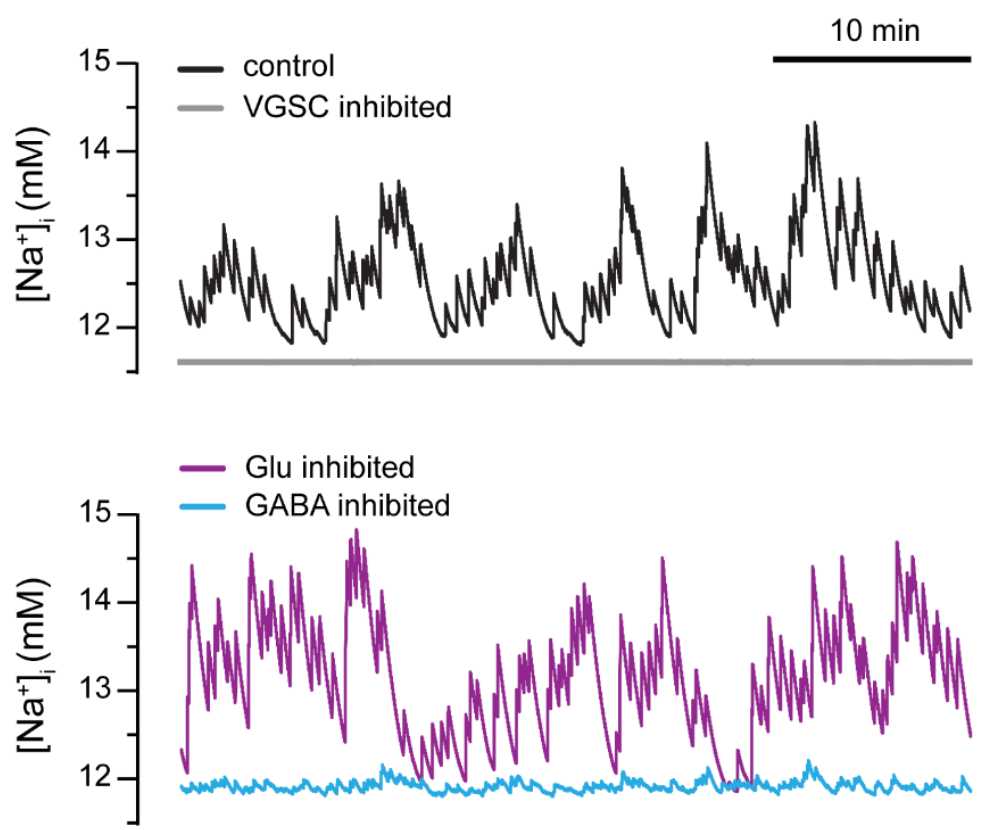

782

Figure 4: Inhibiting $\mathrm{GABA}_{\mathrm{A}}$ receptors or voltage-gated $\mathrm{Na}^{+}$channels eliminates $\left[\mathrm{Na}^{+}\right]_{\mathrm{i}}$

783 fluctuations, whereas blocking glutamatergic synaptic inputs has little effect. (A) Bar plot showing

784 the percentage of neurons exhibiting $\mathrm{Na}^{+}$fluctuations as determined in experiments under the four

785 conditions simulated in (B). That is, the percentage of neurons exhibiting $\mathrm{Na}^{+}$fluctuations in slices

786 from juveniles under control conditions (black) and in the presence of $0.5 \mu \mathrm{M}$ TTX to block

787 voltage gated $\mathrm{Na}^{+}$channels (gray), a cocktail containing APV (100 $\left.\mu \mathrm{M}\right), \mathrm{NBQX}(25 \mu \mathrm{M})$, and

788 MPEP $(25 \mu \mathrm{M})$ to block glutamatergic receptors (purple), and a combined application of

789 bicuculline $(10 \mu \mathrm{M})$, CGP-55845 $(5 \mu \mathrm{M}), \mathrm{NNC}-711(100 \mu \mathrm{M})$, and SNAP-5114 (100 $\mu \mathrm{M})$ to block

790 GABAergic signaling (cyan). (B) Time trace of $\left[\mathrm{Na}^{+}\right]_{\mathrm{i}}$ from a randomly selected excitatory neuron

791 in the network in control conditions (inverted inhibition, representing neonatal brain) (black, top

792 panel), with voltage-gated $\mathrm{Na}^{+}$channels blocked (gray, top panel), glutamatergic synapses blocked

793 (purple, bottom panel), and GABAergic synapses blocked (cyan, bottom panel). 


\section{A. Neuron soma radius}

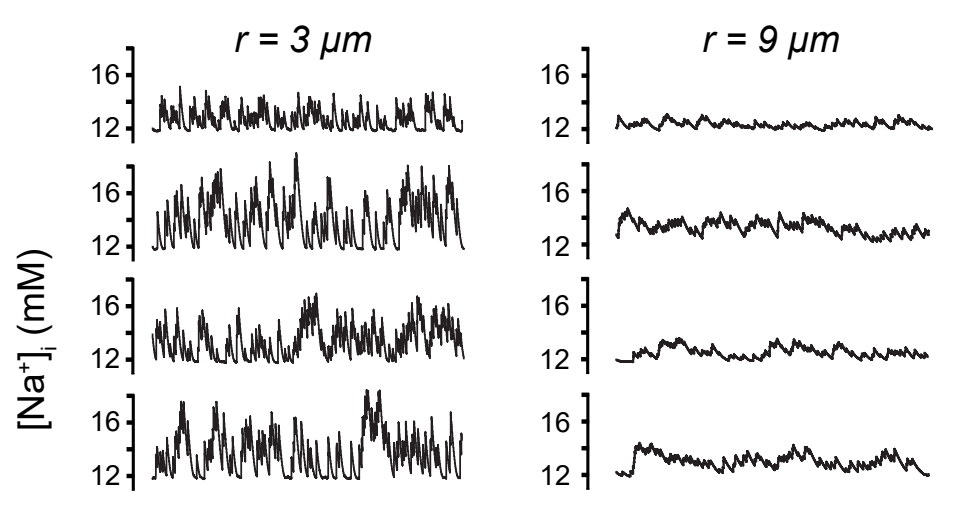

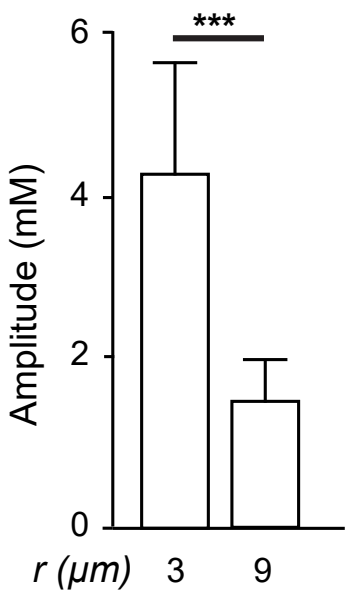

\section{B. Ratio of inter- to extracellular space}

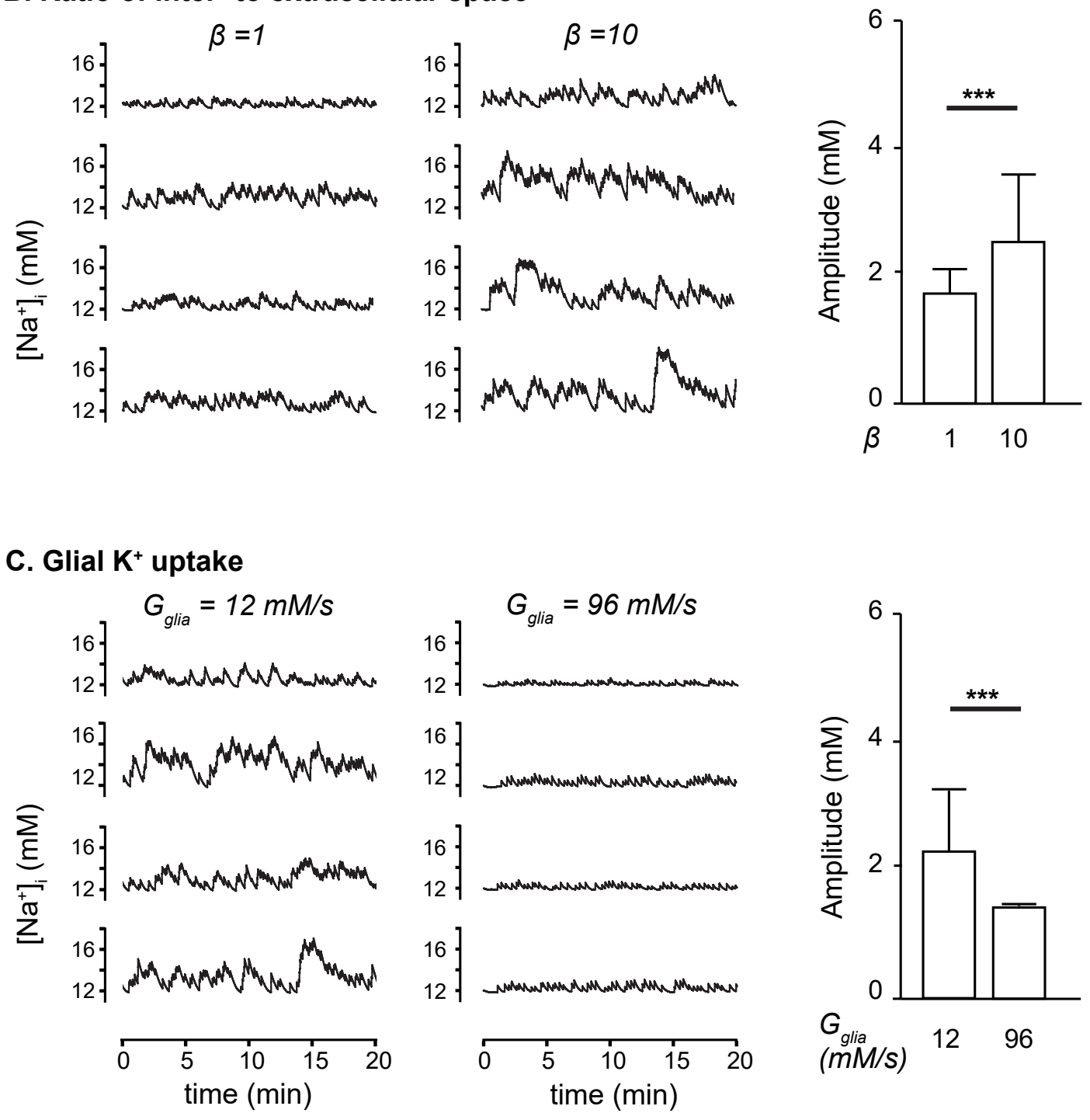


796 Figure 5: The neuronal radius, ratio of ECS to ICS $(\beta)$, and $\mathrm{K}^{+}$uptake capacity of glia affect

797 spontaneous $\mathrm{Na}^{+}$fluctuations. (A) Time traces of $\left[\mathrm{Na}^{+}\right]_{\mathrm{i}}$ for five excitatory neurons from a network

798 representing neonatal brain with a neuronal radius of $3 \mu \mathrm{m}$ (left panels) and $9 \mu \mathrm{m}$ (center panels).

799 The panel on the right shows the mean amplitude of $\mathrm{Na}^{+}$fluctuations (averaged over all pyramidal

800 neurons in the network) under the two conditions. The error bars indicate the standard deviation

801 of the mean. $\beta$ was fixed at 2.5. (B) Same as (A) at $\beta=1$ (left panels) and 10 (center panels). (C)

802 Same as (A) with maximum glial $\mathrm{K}^{+}$buffering strength $\mathrm{G}_{\mathrm{glia}}=12 \mathrm{mM} / \mathrm{s}$ (left panels) and $\mathrm{G}_{\mathrm{glia}}=96$

$803 \mathrm{mM} / \mathrm{s}$ (right panels). The radius of individual neurons is set at $6 \mu \mathrm{m}$ in both $(\mathrm{B})$ and $(\mathrm{C})$. ***:

$804 \quad \mathrm{p}>0.001$.

805 


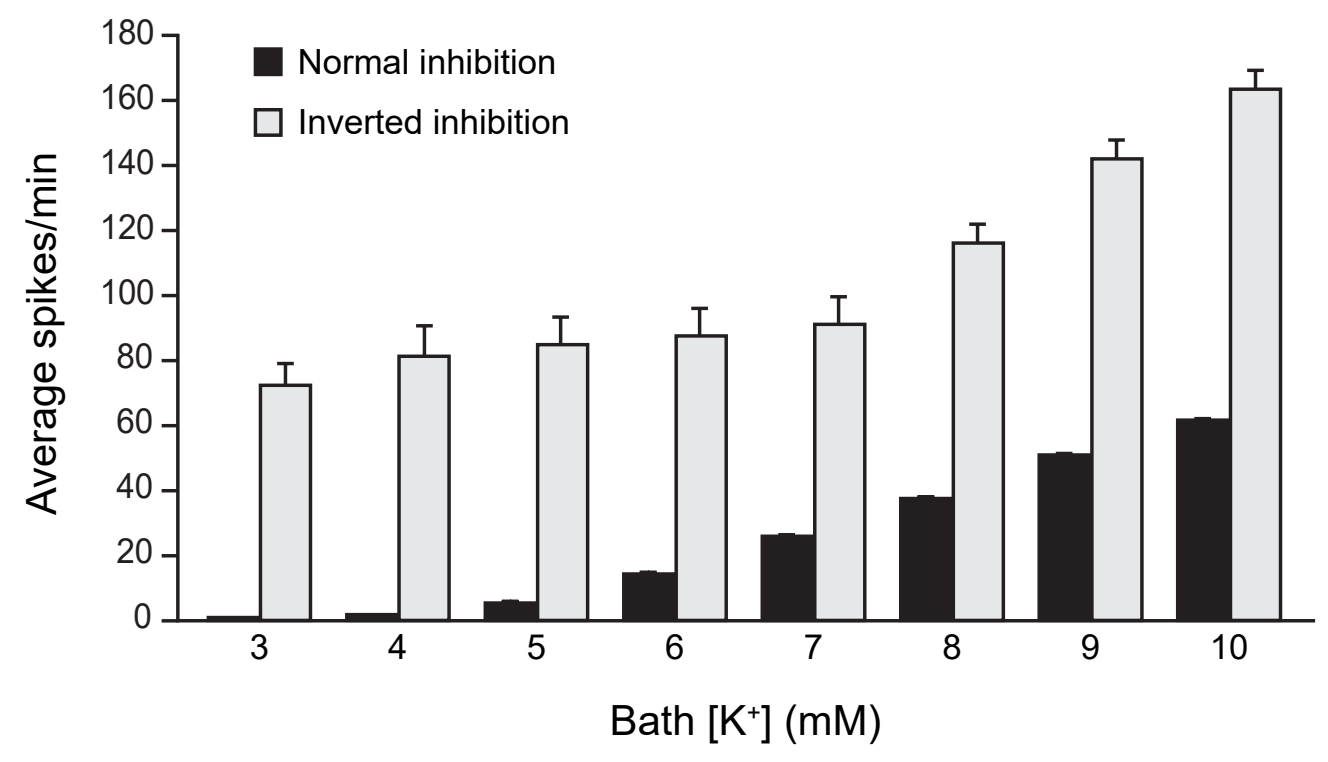

807 Figure 6: Inverted inhibition leaves the network more prone to hyperactivity. (A) Bar plot showing

808 the number of spikes per minute averaged over all excitatory neurons as we systematically increase

$809 \mathrm{~K}^{+}$concentration in the bath. The black and gray bars correspond to neural network with mature

810 and inverted inhibition respectively. The error bars indicate the standard deviation of the mean. 
813

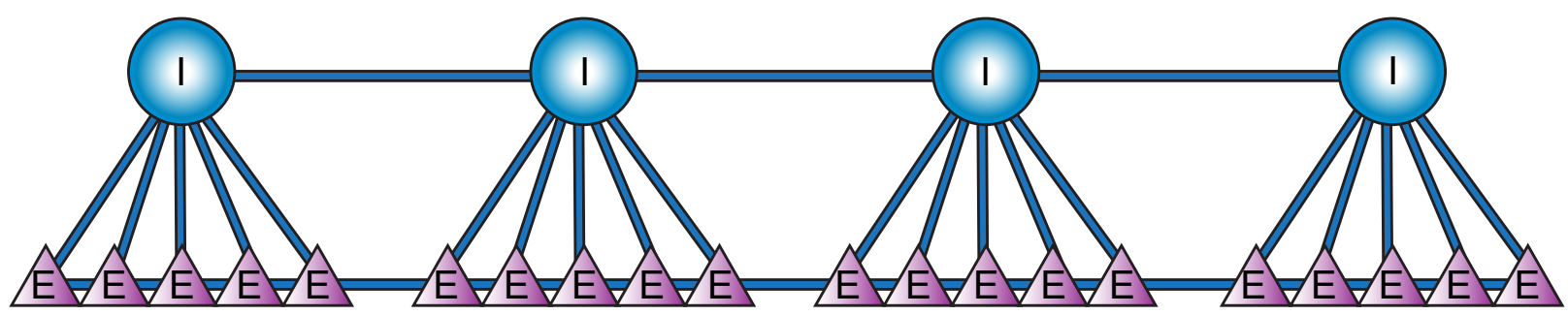

815 Figure 7: Network schematic showing connections between adjacent neurons within the two

816 neuronal layers. The network consists of pyramidal (E) and inhibitory (I) neurons at five to one

817 ratio, where five excitatory and one inhibitory neurons make one domain. In addition to synaptic

818 inputs, we also consider the diffusion of extracellular $\mathrm{K}^{+}$between neighboring cells. Incorporating

$819 \mathrm{Na}^{+}$and $\mathrm{Cl}^{-}$diffusion in the extracellular space does not change our conclusions (not shown) and

820 is therefore not included in the model. 


\begin{tabular}{|c|c|c|}
\hline Parameter & $\begin{array}{l}\text { Value and Unit (Excitatory, } \\
\text { Inhibitory neuron) }\end{array}$ & Description \\
\hline $\mathrm{C}$ & $1.0 \mu \mathrm{F} / \mathrm{cm}^{2}$ & Membrane capacitance \\
\hline$\gamma$ & $3 \times 10^{4} /\left(F \times r_{i n}\right) \mathrm{mM} /(\mathrm{cm} \bullet \mu \mathrm{A})$ & Current to concentration conversion factor \\
\hline$r_{\text {in }}$ & $6 \mu \mathrm{m}$ & Radius of the neuron \\
\hline$\beta$ & 2.5 & Ratio of ICS to ECS \\
\hline$G_{C l}^{L}$ & $0.001 \mathrm{mS} / \mathrm{cm}^{2}$ & Conductance of $\mathrm{Cl}^{-}$leak channels \\
\hline$G_{N a}^{F}$ & $165 \mathrm{mS} / \mathrm{cm}^{2}, 35 \mathrm{mS} / \mathrm{cm}^{2}$ & Maximal conductance of fast $\mathrm{Na}^{+}$channels \\
\hline$G_{K}^{D R}$ & $80 \mathrm{mS} / \mathrm{cm}^{2}, 9 \mathrm{mS} / \mathrm{cm}^{2}$ & $\begin{array}{l}\text { Maximal conductance of delayed rectified } \mathrm{K}^{+} \\
\text {channels }\end{array}$ \\
\hline$G_{K}^{L}$ & $0.02 \mathrm{mS} / \mathrm{cm}^{2}$ & Conductance of $\mathrm{K}^{+}$leak channels \\
\hline$G_{N a}^{L}$ & $7.6 \mu \mathrm{S} / \mathrm{cm}^{2}, 8.55 \mu \mathrm{S} / \mathrm{cm}^{2}$ & Conductance of $\mathrm{Na}^{+}$channels \\
\hline $\mathrm{G}_{\mathrm{AMPA} / \mathrm{NMDA}}$ & $1 \mu \mathrm{S} / \mathrm{cm}^{2}$ & $\begin{array}{l}\text { Maximal conductance of E-to-E and E-to-I } \\
\text { synapses }\end{array}$ \\
\hline$G_{G A B A}^{i i}$ & $10 \mu \mathrm{S} / \mathrm{cm}^{2}$ & Maximal conductance of I-to-I synapses \\
\hline$G_{G A B A}^{i e}$ & $0.1-3.0 \mathrm{mS} / \mathrm{cm}^{2}$ & Maximal conductance of I-to-E synapses \\
\hline$\tau_{R}$ & $0.1 \mathrm{~ms}$ & Rise constant for synaptic gating \\
\hline$\tau_{D}$ & $4.0 \mathrm{~ms}, 30.0 \mathrm{~ms}$ & Decay constant for synaptic gating \\
\hline$f_{\text {stoch }}$ & $1 \mathrm{~Hz}, 0.1 \mathrm{~Hz}$ & Mean arrival frequency of stochastic input \\
\hline$\rho_{\max }$ & $29 \mathrm{mM} / \mathrm{s}$ & Maximum $\mathrm{Na}^{+} / \mathrm{K}^{+}$pump strength \\
\hline$\left[\mathrm{O}_{2}\right]_{\text {bath }}$ & $32 \mathrm{mg} / 1$ & Oxygen concentration in the bath solution \\
\hline$\alpha$ & $5.3 \mathrm{~g} / \mathrm{mol}$ & $\begin{array}{l}\text { Conversion factor from } \mathrm{Na}^{+} / \mathrm{K}^{+} \text {-ATPase } \\
\text { current to oxygen consumption rate }\end{array}$ \\
\hline$\epsilon_{o}$ & $0.17 \mathrm{~s}^{-1}$ & Oxygen diffusion constant \\
\hline $\mathrm{G}_{\text {glia }}$ & $60 \mathrm{mM} / \mathrm{s}$ & Maximum glia $\mathrm{K}^{+}$uptake \\
\hline$\epsilon_{K}$ & $3 \mathrm{~s}^{-1}$ & $\begin{array}{l}\text { Constant for } \mathrm{K}^{+} \text {diffusion between ECS and } \\
\text { bath solution (blood vassals in vivo) }\end{array}$ \\
\hline$\left[K^{+}\right]_{\text {bath }}$ & $3.0 \mathrm{mM}$ & $\begin{array}{l}\mathrm{K}^{+} \text {concentration in the bath solution in vitro } \\
\text { or in vasculature in vivo }\end{array}$ \\
\hline $\mathrm{D}_{\mathrm{K}}$ & $2.5 \times 10^{-5} \mathrm{~cm}^{2} / \mathrm{s}$ & Diffusion coefficient of $\mathrm{K}^{+}$in the ECS \\
\hline $\mathrm{dx}$ & $200 \mu \mathrm{m}$ & Distance between adjacent neurons \\
\hline
\end{tabular}

Table 1: Values and meanings of various parameters used in the model. 